\title{
User involvement in adolescents' mental healthcare: a systematic review
}

\author{
Petter Viksveen ${ }^{1,2} \cdot$. Stig Erlend Bjønness ${ }^{1,3,7} \cdot$ Nicole Elizabeth Cardenas $^{1,4} \cdot$ Julia Rose Game $^{1,5} \cdot$ Siv Hilde Berg ${ }^{1,2}$. \\ Anita Salamonsen $^{6} \cdot$ Marianne Storm $^{7} \cdot$ Karina Aase $^{1,2}$
}

Received: 9 January 2021 / Accepted: 31 May 2021 / Published online: 5 June 2021

(c) The Author(s) 2021

\begin{abstract}
More than one out of ten adolescents suffer from mental illness at any given time. Still, there is limited knowledge about their involvement in mental healthcare. Adolescents have the right to be involved in decisions affecting their healthcare, but limited research focuses on their engagement and decision-making. Therefore, this systematic review aims to explore the existing experiences with, the effectiveness of, and safety issues associated with user involvement for adolescents' mental healthcare at the individual and organizational level. A systematic literature review on user involvement in adolescents' mental healthcare was carried out. A protocol pre-determined the eligibility criteria and search strategies, and established guidelines were used for data extraction, critical appraisal, and reporting of results. Quantitative studies were analysed individually due to heterogeneity of the studies, while qualitative studies were analysed using thematic synthesis. A total of 31 studies were included in the review. The experiences with user involvement were reported in 24 studies with three themes at the individual level: unilateral clinician control versus collaborative relationship, capacity and support for active involvement, the right to be involved; and two themes at the organizational level: involvement outcomes relevant to adolescents' needs, conditions for optimal involvement. The effectiveness of user involvement was reported in seven studies documenting fragmented evidence related to different support structures to facilitate adolescents' involvement. The safety associated with user involvement was not reported in any studies, yet a few examples related to potential risks associated with involvement of adolescents in decision-making and as consultants were mentioned.
\end{abstract}

Keywords User involvement · Adolescents · Mental healthcare $\cdot$ Systematic review

\section{Introduction}

Mental health disorders among adolescents represent longlasting consequences at an individual level and significant economic and public health challenges. They are associated

Petter Viksveen

petter.viksveen@uis.no

$\triangle$ Stig Erlend Bjønness stig.bjonness@uis.no

1 SHARE - Centre for Resilience in Healthcare, Faculty of Health Sciences, University of Stavanger, 4036 Stavanger, Norway

2 Department of Quality and Health Technology, Faculty of Health Sciences, University of Stavanger, 4036 Stavanger, Norway

3 Department of Psychiatry, Stavanger University Hospital, Stavanger, Norway with poorer physical, sexual and social health; limited social networks; poorer education; and lower employment rates [1-4]. Mortality and suicide rates are higher among those who have mental health disorders compared to other adolescents [5, 6]. Many mental disorders in adults have their

4 Faculty of Health Sciences, University of Aberdeen, Aberdeen, Scotland

5 Faculty of Medicine, Pomeranian Medical University in Szczecin, Szczecin, Poland

6 Regional Centre for Child and Youth Mental Health and Child Welfare - North (RKBU North), Faculty of Health Sciences, UiT The Arctic University of Norway, Langnes, P.O. Box 6050, Troms $\varnothing$, Norway

7 Department of Public Health, Faculty of Health Sciences, University of Stavanger, Stavanger, Norway 
onset in childhood or adolescent years [2,7]. More than one out of ten adolescents suffer from mental illness at any given time, but only a minority seek help and many of those who are offered treatment drop-out $[4,6]$. Adolescents have the right to access high quality and safe healthcare services $[8,9]$. Moreover, they have the right to be actively involved in their treatment. This implies that they should be heard, their preferences should be considered, and they should take part in decision-making processes affecting their health [10]. National governments committed themselves to strengthen adolescents' right to be heard in matters affecting their life and health and to participate in decision-making processes, as laid out in the United Nations (UN) General Assembly's Special Session on Children in 2002. User involvement can take place at the individual level, for adolescents to be involved in activities to plan, deliver or review mental health services for their own healthcare; or at the organizational or systems-level for planning, delivering or reviewing healthcare services for other adolescents' mental health, including to develop new or to improve existing services; or at the political level to influence policy decisions, e.g. to develop regulation [11-13].

There is limited knowledge about the existing research in the field of user involvement in adolescents' mental healthcare. A literature review published by in 2005 found that adolescents wanted to be involved in decisions affecting their healthcare [14]. However, at that time involvement of adolescents in their mental healthcare was not so common, and there was limited research assessing it, both in the individual adolescents' mental healthcare and in service development. User involvement has become more prevalent in mental healthcare. Nevertheless, a systematic review carried out in 2012 found only a handful of studies focusing on adolescents' engagement and decision-making in healthcare, and none of those focused on mental healthcare [15]. A scoping review identified some approaches to promote shared decision-making in child mental health, including therapeutic techniques; psychoeducation; discussion prompts; aids for planning, setting goals and making decision; and mobilizing patients to engage. However, evidence of the effectiveness of these approaches was limited and it did not assess the wider context of user involvement, beyond decision-making at the individual level [16]. Furthermore, Liverpool et al. [17] identified decision support interventions for parents of children with attention deficit hyperactivity disorder (ADHD), autistic spectrum disorder (ASD), emotional and behavioural problems including depression (EBD), self-harm or universal mental healthcare. Face-to-face, digital and paper-based interventions were found, e.g. to present treatment options, discuss pros and cons, explore values and preferences, and make recommendations. However, the focus of this review was on interventions for parents, rather than for adolescents themselves. Furthermore, clinicians may also be reluctant to change their practice to introduce shared decision-making [18]. No systematic review has explored user involvement in adolescents' mental healthcare focusing specifically on adolescents' own involvement in their care and for improving mental health services.

This systematic review fills this knowledge gap with the aim to explore existing experiences with, the effectiveness of, and safety issues associated with user involvement for adolescents' mental healthcare, at the individual and organizational level [19]. By experiences, we mean adolescents', healthcare personnel's or other stakeholders' descriptions of involvement of adolescents in planning, delivery or review of mental health services for adolescents' own healthcare (individual level), or for planning, delivering or reviewing mental health services for other adolescents (organizational level). Such experiences could be gathered using qualitative research methods, for example through individual or group interviews. By effectiveness of user involvement, we mean the effect of involvement of adolescents, either at the individual or at the organizational level, measured on specific outcomes assessing involvement itself or health outcomes. Effectiveness could be assessed using controlled or uncontrolled quantitative research designs, e.g. randomized controlled trials, non-randomized controlled trials or uncontrolled studies using quantitative outcome measures. Safety of user involvement could include either adolescents' or other stakeholders' descriptions of experiences (in qualitative studies) or outcome measures (in quantitative studies) suggesting negative impact on adolescents' mental health or safety issues potentially affecting other adolescents or the services themselves such as breach of confidentiality or other violations of General Data Protection Regulations.

This systematic review will contribute to inform clinical practice to determine acceptable, effective, and safe ways of involving adolescents in their healthcare, as well as for developing and improving mental health services.

\section{Methods}

The protocol for this systematic review pre-determined the eligibility criteria, search strategies, guidelines for data extraction, critical appraisal, data synthesis and reporting of results [19].

\section{Inclusion criteria}

We included research articles reporting on involvement of adolescents in mental healthcare at the individual and/or organizational level. Included publications had to fulfil all the criteria presented in Table 1. We used a broad definition of "user involvement" as there is no consensus on how 
Table 1 Article inclusion criteria

\begin{tabular}{|c|c|c|}
\hline Inclusion category & Category description & Notes \\
\hline Adolescents & $\begin{array}{l}\text { Majority within age range } 13-18 \text { years (MeSH } \\
\text { Unique ID: D000293) }\end{array}$ & $\begin{array}{l}\text { Included if more than } 50 \% \text { of the participants were } \\
\text { within the age range }\end{array}$ \\
\hline Study participants & $\begin{array}{l}\text { Any participants reporting on adolescents' } \\
\text { involvement in mental healthcare }\end{array}$ & $\begin{array}{l}\text { E.g. adolescents, caretakers, healthcare profession- } \\
\text { als }\end{array}$ \\
\hline Mental healthcare & $\begin{array}{l}\text { Healthcare services providing preventive or } \\
\text { therapeutic interventions for diagnosed or self- } \\
\text { reported mental health and/or substance use } \\
\text { problems }\end{array}$ & Based on MeSH Unique ID: D003191 \\
\hline User involvement (individual level) & $\begin{array}{l}\text { Involvement of the individual adolescent in her or } \\
\text { his own mental healthcare }\end{array}$ & $\begin{array}{l}\text { Experiences, views and wishes to plan, deliver, } \\
\text { review or make other decisions affecting adoles- } \\
\text { cents' mental healthcare }\end{array}$ \\
\hline User involvement (organizational level) & $\begin{array}{l}\text { Adolescents' experiences, views and wishes used } \\
\text { to plan, deliver or review mental health services } \\
\text { for adolescents in general, including to develop } \\
\text { new or to improve existing services }\end{array}$ & $\begin{array}{l}\text { Including adolescents' experiences with mental } \\
\text { health services used in practice implementation } \\
\text { or testing in research }\end{array}$ \\
\hline Research methods & $\begin{array}{l}\text { Studies using qualitative, quantitative or mixed } \\
\text { methods }\end{array}$ & \\
\hline Publication types & Peer-reviewed and grey literature & $\begin{array}{l}\text { Grey literature: academic theses and dissertations; } \\
\text { conference abstracts, proceedings, papers; gov- } \\
\text { ernmental and non-governmental reports }\end{array}$ \\
\hline Languages & $\begin{array}{l}\text { English, German, French, Danish, Norwegian, } \\
\text { Swedish }\end{array}$ & \\
\hline Publication year & $2002-2019$ & \\
\hline
\end{tabular}

the term should be understood and we attempted to include all articles that could contribute to expand current knowledge in this underexplored field of research. Involvement of adolescents could include gathering their experiences, views and perspectives as part of planning, delivering or reviewing their own (individual level) or other adolescents' (systems-level) mental healthcare. Communication alone, e.g. between adolescents and health personnel during a therapy session, was not sufficient to be considered "user involvement". Health personnel were understood as any person working as an individual practitioner or employees of a health institution (e.g. MeSH Unique ID D006282). Only original articles were included. Literature reviews were only used to identify additional relevant research articles. The inclusion of Nordic languages was due to the rising focus on user involvement in mental healthcare in the Nordic countries over the past decades, which also is the context within which we carry out our research. The period (2002-2019) was set to cover the literature most relevant to

Table 2 Literature search strategy

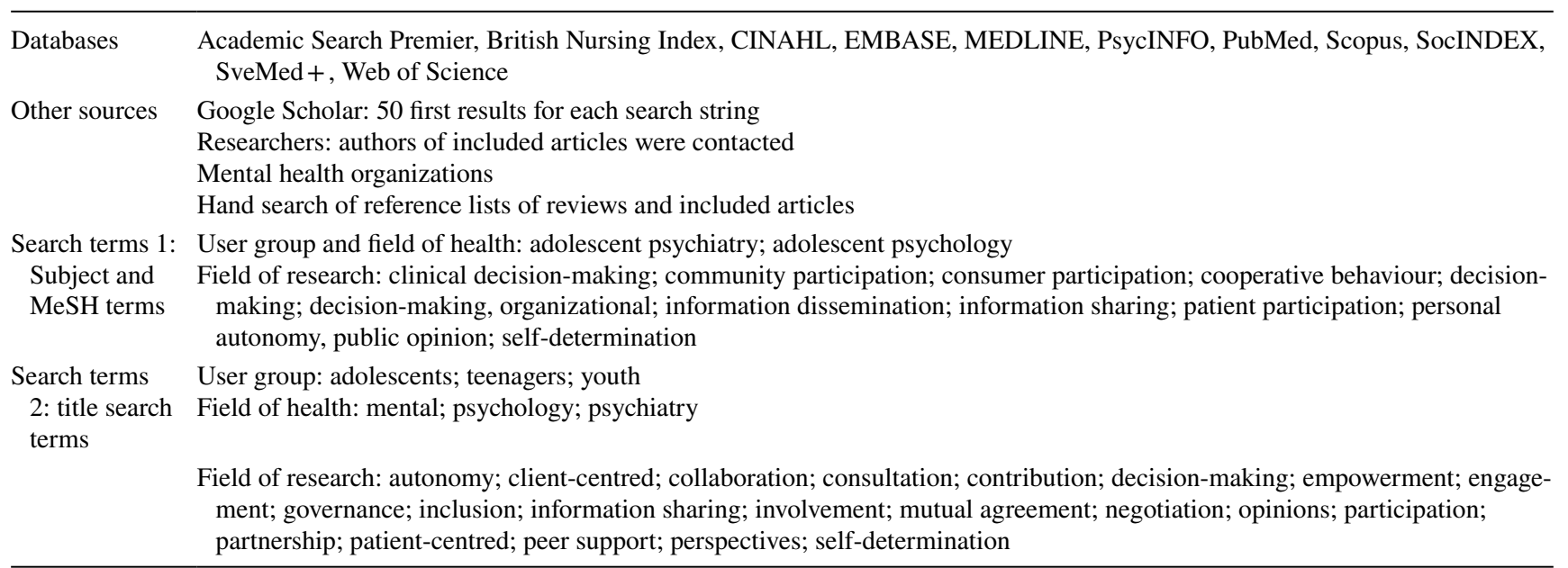


current clinical practice and following the 2002 UN General Assembly's Children's rights policy.

\section{Search strategy}

The literature search strategy included 11 databases and other sources to identify both peer-reviewed articles and grey literature (Table 2). A broad range of search terms were used in order to identify potentially relevant articles reporting on "user involvement" as this could include a variety of different activities (Table 2). We customized searches to each database with an aim to maximize sensitivity and specificity. A university librarian was consulted to plan the literature search strategy. Searches were carried out until 16.06.2019 independently by two researchers (PV, SEB), and results were compared. There were minor differences in search results due to searches being carried out a few days apart. Any discrepancies in search results were discussed and all articles identified by at least one of the researchers were included. An example of a full electronic search is presented in Appendix 1. Two researchers (PV, SEB) screened titles and abstracts. The full texts of potentially relevant articles were screened by at least two researchers (AS, PV, KAA, MS, SEB, SHB). Where there were discrepancies in researchers' assessment, a third researcher and a co-researcher (JRG, NEC) were involved, and consensus for inclusion/exclusion was reached for all articles. All researchers were involved in the full-text screening process (PV, SEB, AS, KAA, MS, SHB). Endnote (version X9) was used to manage data records.

\section{Data extraction}

Data extractions guidelines included the Critical Appraisal Skills Programme (CASP) for qualitative studies [20], the Cochrane Consumers and Communication Review Group's data extraction template for trials [21], and the STROBE statement checklist for cohort, case-control and cross-sectional studies [22]. Included articles were divided between the six researchers for data extraction (PV, SEB, AS, KAA, MS, SHB). Data was extracted by one researcher and checked by a second researcher. Agreement on data extraction was reached between researchers. Where available, main outcomes were reported for studies using quantitative methods. For articles reporting multiple outcomes, only those of relevance to the systematic review were included. Information on what data were reported is provided under the section entitled "Reporting of results".

\section{Quality appraisal}

Studies using quantitative methods were assessed using the Cochrane Collaboration's guidelines for assessment of risk of bias [23]. This included assessment of risk of selection, performance, detection, attrition and reporting bias (each assessed as either low, high or unclear risk of bias); as well as the potential influence of confounding factors for non-randomized studies, as suggested by Reeves et al. [24]. The risk of meta-bias (publication bias across studies and selective reporting within studies) [25] was considered by searching for unpublished studies in the grey literature, and through comparison of the methods and the results sections of included studies when no protocol articles were found. The applicability and generalizability of results of quantitative studies was considered using the Pragmatic Explanatory Continuum Indicator Summary (PRECIS) tool [26].

Studies using qualitative methods were appraised using the Critical Appraisal Skills Programme (CASP) to determine rigour, credibility and relevance of the research [20]. Each CASP item was assessed and considered satisfactory ("yes"), not satisfactory ("no"), or providing insufficient information to be assessed ("unclear"). Study quality categories were scored as suggested by others [27], depending on the number of items scoring "yes" (low: 0-5, moderate: 6-8, high: 9-10 items).

\section{Reporting of results}

Results of the literature search are presented using the Preferred Reporting Items for Systematic reviews and MetaAnalyses (PRISMA) flow diagram [28]. Data from randomized controlled trials are reported using the Consolidated Standards of Reporting Trials (CONSORT) statement [29], the Strengthening the Reporting of Observational Studies in Epidemiology (STROBE) statement for observational (cohort and cross-sectional) studies [22], and the CASP checklist for qualitative studies [20].

Characteristics of qualitative studies were tabulated to provide information about participant characteristics (age, gender, mental health status/conditions/problems) with number of participants; intervention/treatment and study setting, methods (research design, recruitment methods, data collection, analytic method); the level of involvement (individual, organizational); and the overall result of a quality assessment. We also report the result of a thematic synthesis of qualitative studies.

Characteristics and results of quantitative studies were tabulated to include information on study design; participant characteristics; interventions and study setting; trial arms, with number of participants in each arm; results of studies, with focus on outcomes of relevance to the systematic 
review; and assessment of internal validity focusing on risk of bias [23] and external validity, using the PRECIS tool for assessing studies on a pragmatic-explanatory continuum [26]. Key characteristics and results of quantitative studies are also presented for each individual study in text, but with no synthesis of data due to the heterogeneity of the identified studies.

\section{Thematic synthesis of qualitative studies}

A thematic synthesis was developed to report on experiences with involvement of adolescents at the individual and the organizational level. The purpose of the thematic synthesis was to analyse results across different contexts and participants, and to go beyond the content of the original studies to possibly develop new explanations, constructs or hypotheses [30,31]. The analysis draws on techniques used in thematic analysis, and suggests that the results may be more than merely the sum of the individual studies [32]. Three researchers (KAA, PV, SEB) carried out the thematic synthesis process, but consulted with the co-researchers (JRG, NEC) who contributed to revising the themes. We used the approach suggested by Thomas and Harden [31], by initially identifying all the text in the "results" or "findings" sections of abstracts and full texts of the included qualitative studies. The selected text was marked line-by-line by one researcher (PV) to identify codes of potential relevance to the research aim, and checked by a second researcher (SEB). Coding was discussed and consensus was reached. This was followed by development of descriptive themes, based on codes and developed through an inductive process using no prior theoretical model, but by using the definition described in the inclusion criteria.

The analytic process included analysis and re-analysis through several phases where we revisited the original studies, reassessed the extracted data, and reconsidered codes, themes and descriptions of themes. This could include abandoning preliminary themes or sub-themes that only to a limited extent were supported by extracted data. For example, "leadership support" served as one of the preliminary themes for user involvement at the organizational level but was in the final analysis included in the theme of "conditions for optimal involvement".

\section{Results}

The results were divided into three main sections: (1) experiences with user involvement, reported through studies using qualitative research methods; (2) effectiveness of user involvement, reported through studies using quantitative research methods; and (3) safety associated with user involvement, reported in either qualitative or quantitative studies. First, search results, sources, characteristics, and quality assessment of the included articles are reported.

\section{Literature search results}

A total of 4,978 titles were identified through 11 databases and other sources, and 31 articles were included in the systematic review. Most articles were excluded during the screening of titles and abstracts, leaving 229 articles for full-text assessment. Consensus on inclusion/exclusion was reached for all except two articles, where a majority vote was used to make a final decision. Adolescent co-researchers were consulted for six articles where there were initial discrepancies in researchers' assessments. Further details with reasons for inclusion and exclusion of articles are provided in the PRISMA flow diagram (Fig. 1).

\section{Sources of included articles}

Most included articles $(n=26)$ were identified through database searches, but six were only found using other sources (Table 3). No single database identified more than 12 included articles, and half of the included titles were only found through a single source. Four articles were suggested by some of the 22 researchers in the field of user involvement in adolescents' mental healthcare we contacted, and two titles that were found by searching reference lists of included articles.

\section{Characteristics of qualitative studies}

Twenty-four studies reporting on qualitative data were included, with a total of 587 participants (median 22, IQR 15-30) (Table 4). The majority of participants were adolescents $(n=491,84 \%)$, whereas the remaining were parents, guardians or care providers $(n=64,11 \%)$, and healthcare staff $(n=32,6 \%)$, reporting on adolescent involvement. Although there was considerable variation in adolescents' gender distribution between studies (female range $20 \%-100 \%$ ), the overall proportion of females and males was equal. Studies were carried out within a wide range of primary and secondary healthcare services (details in Table 4). Most studies $(n=15)$ included either adolescents with specified diagnosed mental health conditions, such as depression, eating disorders, and ADHD; or adolescents with self-reported mental health problems including selfharm, suicidal thoughts or behaviours, and drug or alcohol problems. Mental health problems were not specified in the remaining nine studies. User involvement at the individual level was reported in 17 studies and at the organizational level in 11 studies (four at both levels). 
Fig. 1 Systematic review PRISMA flow diagram

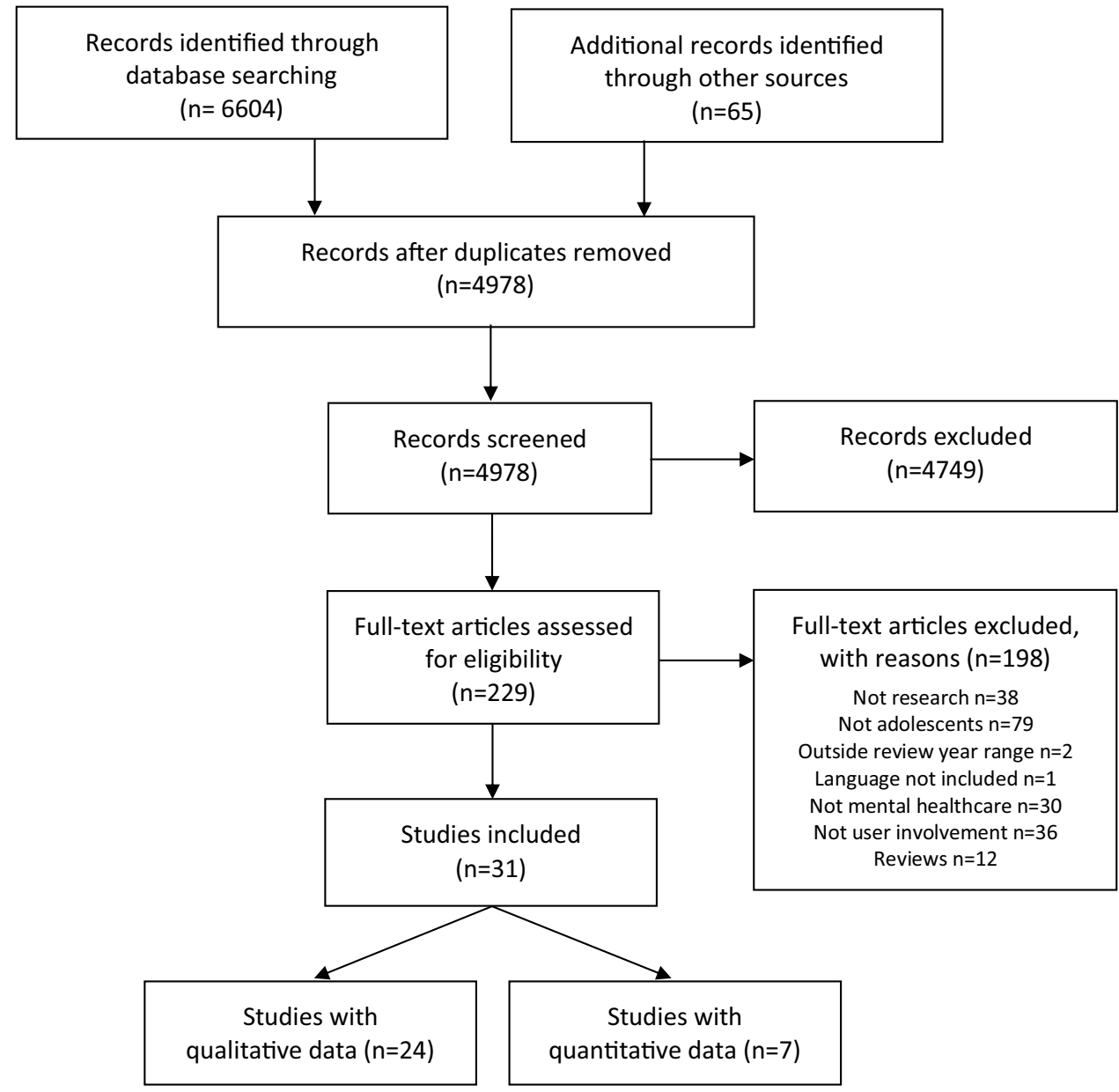

Table 3 Sources of included articles

\begin{tabular}{lll}
\hline Sources & Number of articles & $\begin{array}{l}\text { Unique } \\
\text { source }^{\mathrm{a}}\end{array}$ \\
\hline Total & $\mathbf{3 1}$ & $\mathbf{1 5}$ \\
Databases & 26 & 9 \\
PsycINFO & 12 & 2 \\
EMBASE & 10 & 3 \\
Academic Search Premier & 9 & 0 \\
CINAHL & 9 & 0 \\
Web of Science & 9 & 0 \\
MEDLINE & 5 & 1 \\
PubMed & 5 & 1 \\
British Nursing Index & 3 & 1 \\
SocINDEX & 3 & 0 \\
Scopus & 1 & 1 \\
SveMed + & 0 & 0 \\
Other & $\mathbf{7}$ & $\mathbf{6}$ \\
Researchers & 5 & 4 \\
Reference lists & 2 & 2 \\
Google Scholar & 0 & 0 \\
Mental health organizations & 0 & 0 \\
\hline
\end{tabular}

${ }^{a}$ Number of articles only identified through a single source

\section{Quality assessment of qualitative studies}

All studies satisfied the first two criteria of the Critical Appraisal Skills Programme (CASP) guidelines [20], including a clear aim of the research and the appropriateness of using qualitative methodology to address the research goal (Table 5). The CASP guidelines suggest that it is then worth proceeding with an assessment of the remaining questions.

Overall, most studies $(n=14)$ were of moderate quality, one-third were of high quality, and two studies were of low quality. The most common weakness in the studies was a lack of consideration or reporting of the relationship between the researchers and the participants, which was only adequately done and sufficiently described in four studies. Other prevalent limitations included a lack of rigour in reporting of data analysis methods $(n=8)$, participant recruitment strategies $(n=7)$, and consideration of ethical issues $(n=7)$. A complete overview of CASP questions and criteria may be found in Appendix 2. 


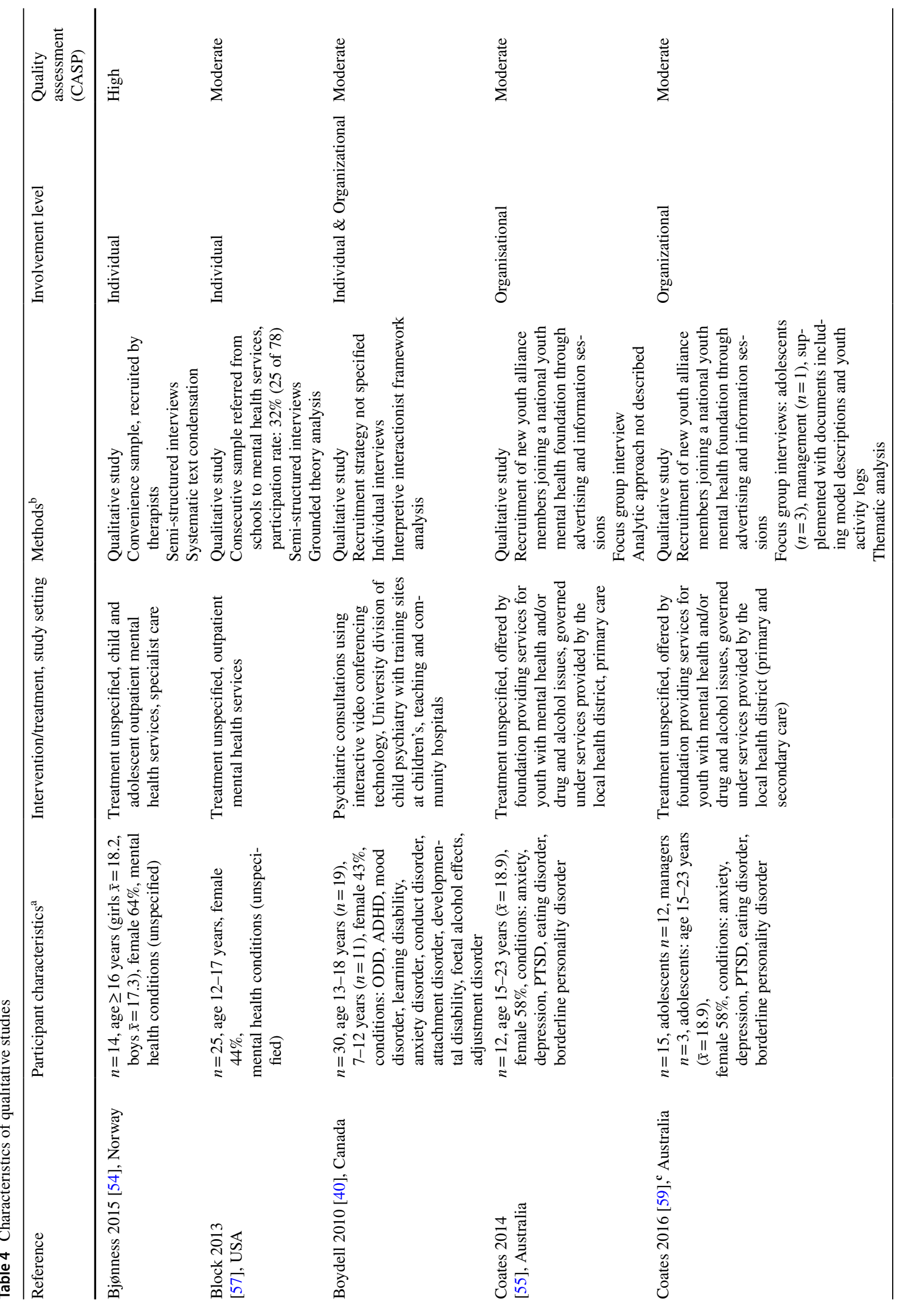




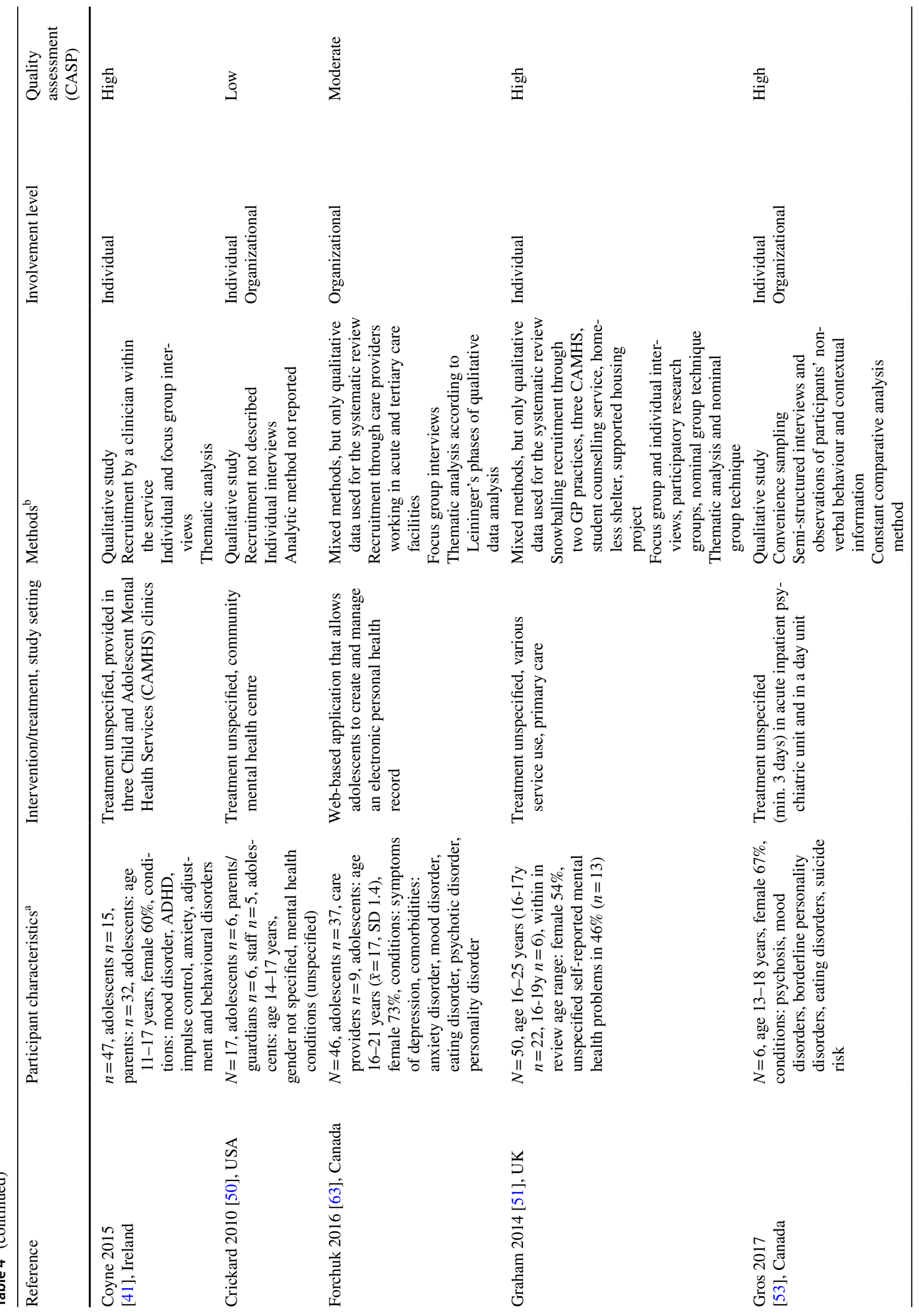




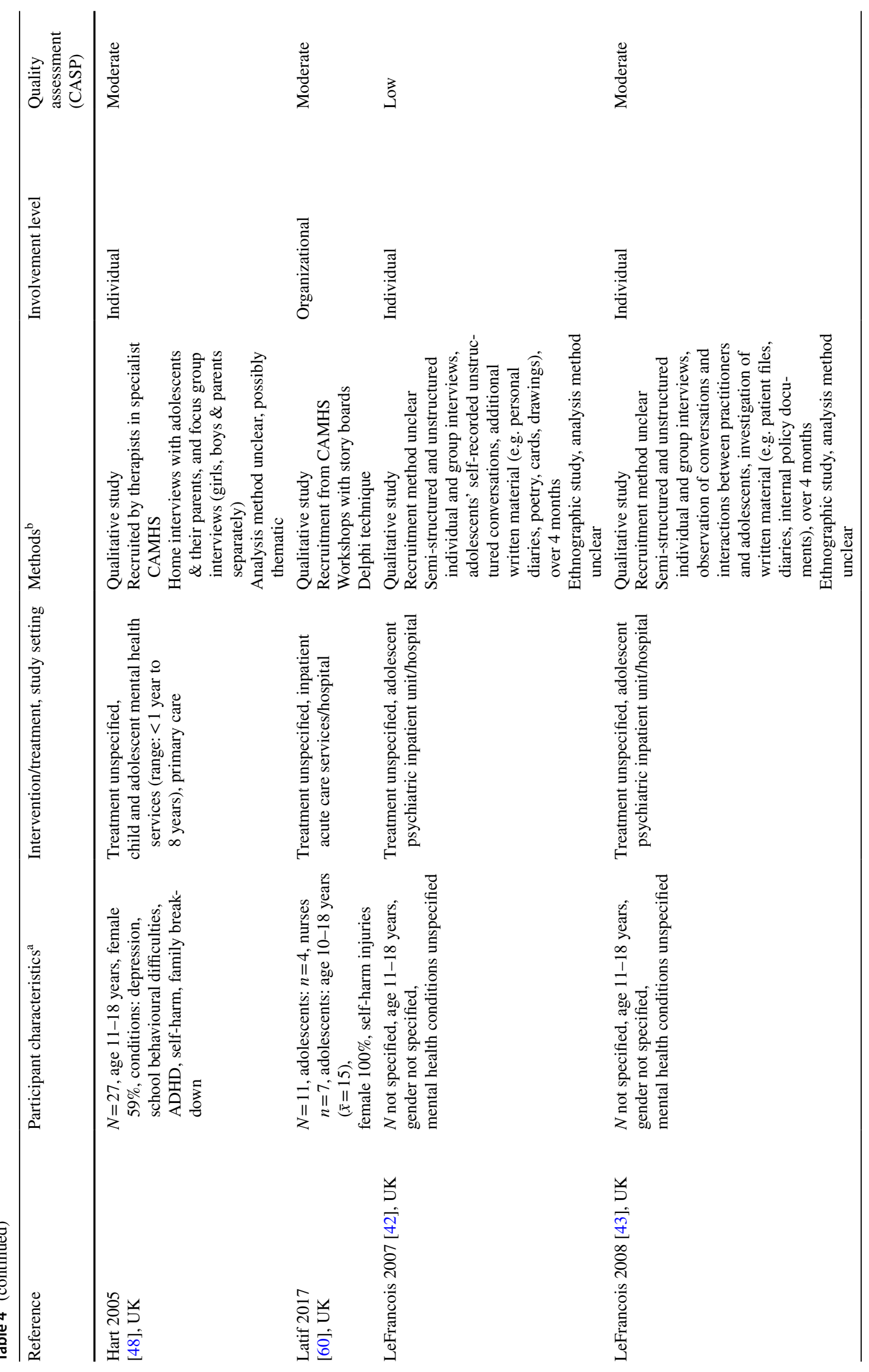




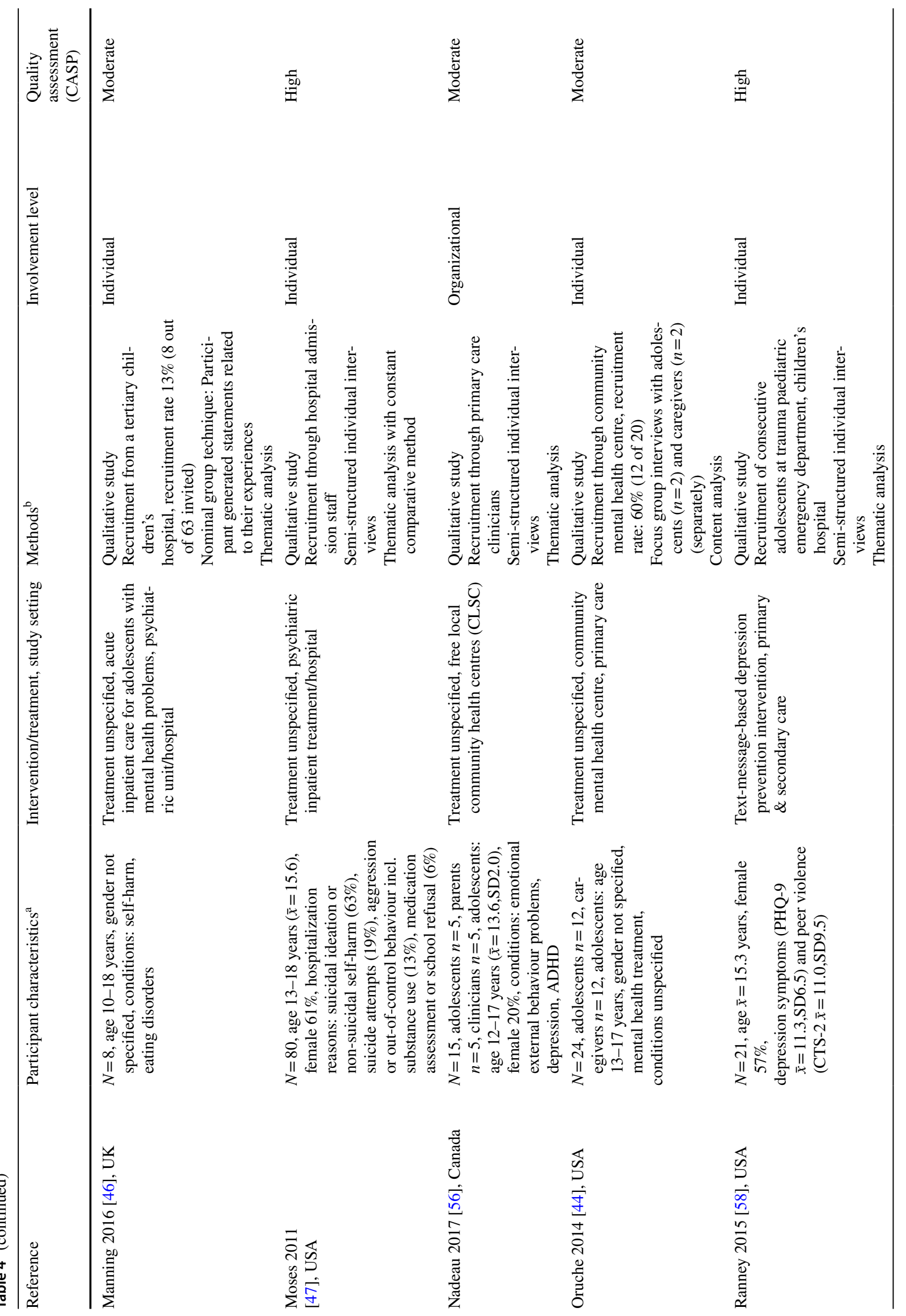




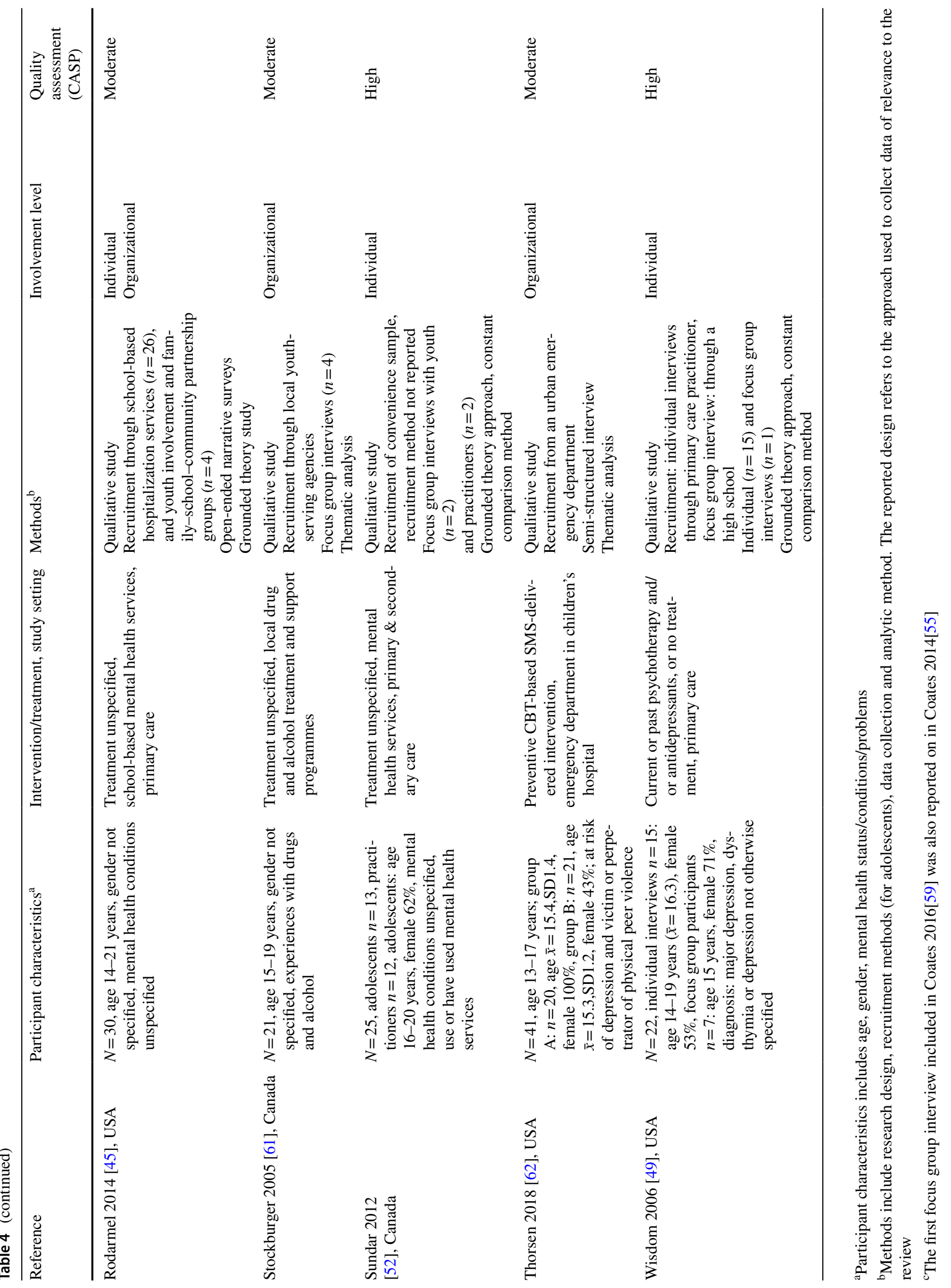


Table 5 Quality assessment of qualitative studies

\begin{tabular}{|c|c|c|c|c|c|c|c|c|c|c|c|c|}
\hline Main author, year & 1 & 2 & 3 & 4 & 5 & 6 & 7 & 8 & 9 & 10 & $\begin{array}{l}\text { Involve- } \\
\text { ment } \\
\text { level }^{\mathrm{a}}\end{array}$ & Assessment (CASP) ${ }^{b}$ \\
\hline Bjønness 2015 [54] & $\mathrm{Y}$ & $\mathrm{Y}$ & $\mathrm{Y}$ & $\mathrm{Y}$ & $\mathrm{Y}$ & $\mathrm{Y}$ & $\mathrm{Y}$ & $\mathrm{Y}$ & $\mathrm{Y}$ & $\mathrm{Y}$ & I & High \\
\hline Block 2013 [57] & $\mathrm{Y}$ & $\mathrm{Y}$ & $\mathrm{Y}$ & $\mathrm{Y}$ & $\mathrm{Y}$ & $\mathrm{U}$ & $\mathrm{Y}$ & $\mathrm{U}$ & $\mathrm{Y}$ & $\mathrm{U}$ & I & Moderate \\
\hline Boydell 2010 [40] & $\mathrm{Y}$ & $\mathrm{Y}$ & $\mathrm{Y}$ & $\mathrm{U}$ & $\mathrm{Y}$ & $\mathrm{U}$ & $\mathrm{N}$ & $\mathrm{Y}$ & $\mathrm{Y}$ & Y & $\mathrm{I} / \mathrm{O}$ & Moderate \\
\hline Coates 2014 [55] & $\mathrm{Y}$ & $\mathrm{Y}$ & $\mathrm{U}$ & $\mathrm{Y}$ & $\mathrm{Y}$ & $\mathrm{U}$ & $\mathrm{Y}$ & $\mathrm{U}$ & $\mathrm{Y}$ & $\mathrm{U}$ & $\mathrm{O}$ & Moderate \\
\hline Coates 2016 [59] & $\mathrm{Y}$ & $\mathrm{Y}$ & $\mathrm{Y}$ & $\mathrm{Y}$ & $\mathrm{Y}$ & $\mathrm{N}$ & $\mathrm{Y}$ & $\mathrm{U}$ & $\mathrm{Y}$ & Y & $\mathrm{O}$ & Moderate \\
\hline Coyne 2015 [41] & $\mathrm{Y}$ & $\mathrm{Y}$ & $\mathrm{Y}$ & $\mathrm{Y}$ & $\mathrm{Y}$ & $\mathrm{N}$ & $\mathrm{Y}$ & $\mathrm{Y}$ & $\mathrm{Y}$ & $\mathrm{Y}$ & I & High \\
\hline Crickard 2010 [50] & $\mathrm{Y}$ & $\mathrm{Y}$ & $\mathrm{Y}$ & $\mathrm{U}$ & $\mathrm{Y}$ & $\mathrm{U}$ & $\mathrm{N}$ & $\mathrm{U}$ & $\mathrm{N}$ & $\mathrm{Y}$ & $\mathrm{I} / \mathrm{O}$ & Low \\
\hline Forchuk 2016 [63] & $\mathrm{Y}$ & $\mathrm{Y}$ & $\mathrm{Y}$ & $\mathrm{U}$ & $\mathrm{Y}$ & $\mathrm{U}$ & $\mathrm{U}$ & $\mathrm{U}$ & $\mathrm{Y}$ & $\mathrm{Y}$ & $\mathrm{O}$ & Moderate \\
\hline Graham 2014 [51] & $\mathrm{Y}$ & $\mathrm{Y}$ & $\mathrm{Y}$ & $\mathrm{Y}$ & $\mathrm{Y}$ & $\mathrm{Y}$ & $\mathrm{Y}$ & $\mathrm{Y}$ & $\mathrm{Y}$ & Y & I & High \\
\hline Gros 2017 [53] & $\mathrm{Y}$ & $\mathrm{Y}$ & $\mathrm{Y}$ & $\mathrm{Y}$ & $\mathrm{Y}$ & $\mathrm{Y}$ & $\mathrm{Y}$ & $\mathrm{Y}$ & $\mathrm{Y}$ & $\mathrm{Y}$ & $\mathrm{I} / \mathrm{O}$ & High \\
\hline Hart 2005 [48] & $\mathrm{Y}$ & $\mathrm{Y}$ & $\mathrm{Y}$ & Y & $\mathrm{Y}$ & $\mathrm{N}$ & $\mathrm{Y}$ & $\mathrm{U}$ & $\mathrm{Y}$ & $\mathrm{Y}$ & I & Moderate \\
\hline Latif 2017 [60] & $\mathrm{Y}$ & $\mathrm{Y}$ & $\mathrm{Y}$ & $\mathrm{U}$ & $\mathrm{Y}$ & $\mathrm{U}$ & $\mathrm{Y}$ & $\mathrm{U}$ & $\mathrm{Y}$ & $\mathrm{Y}$ & $\mathrm{O}$ & Moderate \\
\hline LeFrancois 2007 [42] & $\mathrm{Y}$ & $\mathrm{Y}$ & $\mathrm{Y}$ & $\mathrm{U}$ & $\mathrm{Y}$ & $\mathrm{U}$ & $\mathrm{N}$ & $\mathrm{U}$ & $\mathrm{Y}$ & $\mathrm{U}$ & I & Low \\
\hline LeFrancois 2008 [43] & $\mathrm{Y}$ & $\mathrm{Y}$ & $\mathrm{Y}$ & $\mathrm{U}$ & $\mathrm{Y}$ & $\mathrm{U}$ & $\mathrm{N}$ & $\mathrm{U}$ & $\mathrm{Y}$ & $\mathrm{Y}$ & I & Moderate \\
\hline Manning 2016 [46] & $\mathrm{Y}$ & $\mathrm{Y}$ & $\mathrm{Y}$ & $\mathrm{Y}$ & $\mathrm{Y}$ & $\mathrm{N}$ & $\mathrm{N}$ & $\mathrm{U}$ & $\mathrm{Y}$ & $\mathrm{U}$ & I & Moderate \\
\hline Moses 2011 [47] & $\mathrm{Y}$ & $\mathrm{Y}$ & $\mathrm{Y}$ & $\mathrm{Y}$ & $\mathrm{Y}$ & $\mathrm{N}$ & $\mathrm{Y}$ & $\mathrm{Y}$ & $\mathrm{Y}$ & $\mathrm{Y}$ & I & High \\
\hline Nadeau 2017 [56] & $\mathrm{Y}$ & $\mathrm{Y}$ & $\mathrm{Y}$ & $\mathrm{Y}$ & $\mathrm{Y}$ & $\mathrm{U}$ & $\mathrm{Y}$ & $\mathrm{Y}$ & $\mathrm{Y}$ & $\mathrm{U}$ & $\mathrm{O}$ & Moderate \\
\hline Oruche 2014 [44] & $\mathrm{Y}$ & $\mathrm{Y}$ & $\mathrm{Y}$ & $\mathrm{Y}$ & $\mathrm{Y}$ & $\mathrm{U}$ & $\mathrm{Y}$ & $\mathrm{Y}$ & $\mathrm{Y}$ & $\mathrm{U}$ & I & Moderate \\
\hline Ranney 2015 [58] & $\mathrm{Y}$ & $\mathrm{Y}$ & $\mathrm{Y}$ & $\mathrm{Y}$ & $\mathrm{Y}$ & $\mathrm{N}$ & $\mathrm{Y}$ & $\mathrm{Y}$ & $\mathrm{Y}$ & $\mathrm{Y}$ & I & High \\
\hline Rodarmel 2014 [45] & $\mathrm{Y}$ & $\mathrm{Y}$ & $\mathrm{Y}$ & $\mathrm{Y}$ & $\mathrm{Y}$ & NA & $\mathrm{Y}$ & $\mathrm{Y}$ & $\mathrm{Y}$ & $\mathrm{U}$ & $\mathrm{I} / \mathrm{O}$ & Moderate \\
\hline Stockburger 2005 [61] & $\mathrm{Y}$ & $\mathrm{Y}$ & Y & $\mathrm{U}$ & $\mathrm{Y}$ & $\mathrm{Y}$ & $\mathrm{Y}$ & $\mathrm{U}$ & $\mathrm{Y}$ & $\mathrm{Y}$ & $\mathrm{O}$ & Moderate \\
\hline Sundar 2012 [52] & $\mathrm{Y}$ & $\mathrm{Y}$ & $\mathrm{Y}$ & $\mathrm{Y}$ & $\mathrm{Y}$ & $\mathrm{N}$ & $\mathrm{Y}$ & $\mathrm{Y}$ & $\mathrm{Y}$ & $\mathrm{Y}$ & I & High \\
\hline Thorsen 2018 [62] & $\mathrm{Y}$ & $\mathrm{Y}$ & $\mathrm{Y}$ & $\mathrm{Y}$ & $\mathrm{Y}$ & $\mathrm{U}$ & $\mathrm{N}$ & $\mathrm{Y}$ & $\mathrm{Y}$ & $\mathrm{Y}$ & $\mathrm{O}$ & Moderate \\
\hline Wisdom 2006 [49] & $\mathrm{Y}$ & $\mathrm{Y}$ & Y & Y & $\mathrm{Y}$ & $\mathrm{U}$ & $\mathrm{Y}$ & $\mathrm{Y}$ & Y & $\mathrm{Y}$ & I & High \\
\hline
\end{tabular}

a. $\mathrm{I}=$ Individual level, $0=$ Organizational level. b. CASP criteria are presented in appendix $2 . \mathrm{Y}=\mathrm{Yes}$, $\mathrm{N}=\mathrm{No}, \mathrm{U}=$ Unclear, $\mathrm{NA}=$ Not applicable. Scoring: Low: Studies meeting 0-5 of the CASP

checklist criteria. Moderate: studies meeting 6-8 of the criteria. High: studies meeting 9-10 of the criteria. For question 10, the score was considered to be Yes if the study was considered to be of "relevance" or "some relevance" to the systematic review, and Unclear if it was considered to be of "limited relevance"

\section{Characteristics of quantitative studies}

Seven studies used quantitative methods, out of which six reported on user involvement at the individual level [33-38], and one at the organizational level [39]. This included a single randomized controlled trial [38]; a non-randomized comparative study [36]; two longitudinal prospective cohort studies [33, 34]; a cohort study using pre- to post-assessment [37]; and two cross-sectional surveys [35, 39], out of which one also used repeated measures for some participants [39]. There was considerable heterogeneity between studies. Further study characteristics are presented in Table 6 .

\section{Quality assessment of quantitative studies}

The six studies reporting on user involvement at the individual level were all considered to have a high risk of bias, according to the Cochrane Collaboration's guidelines
[23]. The study assessing user involvement at the organizational level included two types of psychometric tests as part of assessing an outcome measure [39]. Three of the studies were, according to assessments carried out using the PRECIS tool [26], considered to be more pragmatic than explanatory [36-38]; and the remaining three were equally pragmatic and explanatory [33-35]. Further details are presented in Table 6 .

\section{Experiences with user involvement}

Thematic syntheses were carried out separately for user involvement at the individual and at the organizational level. Each theme is described and references to the research literature are provided. 


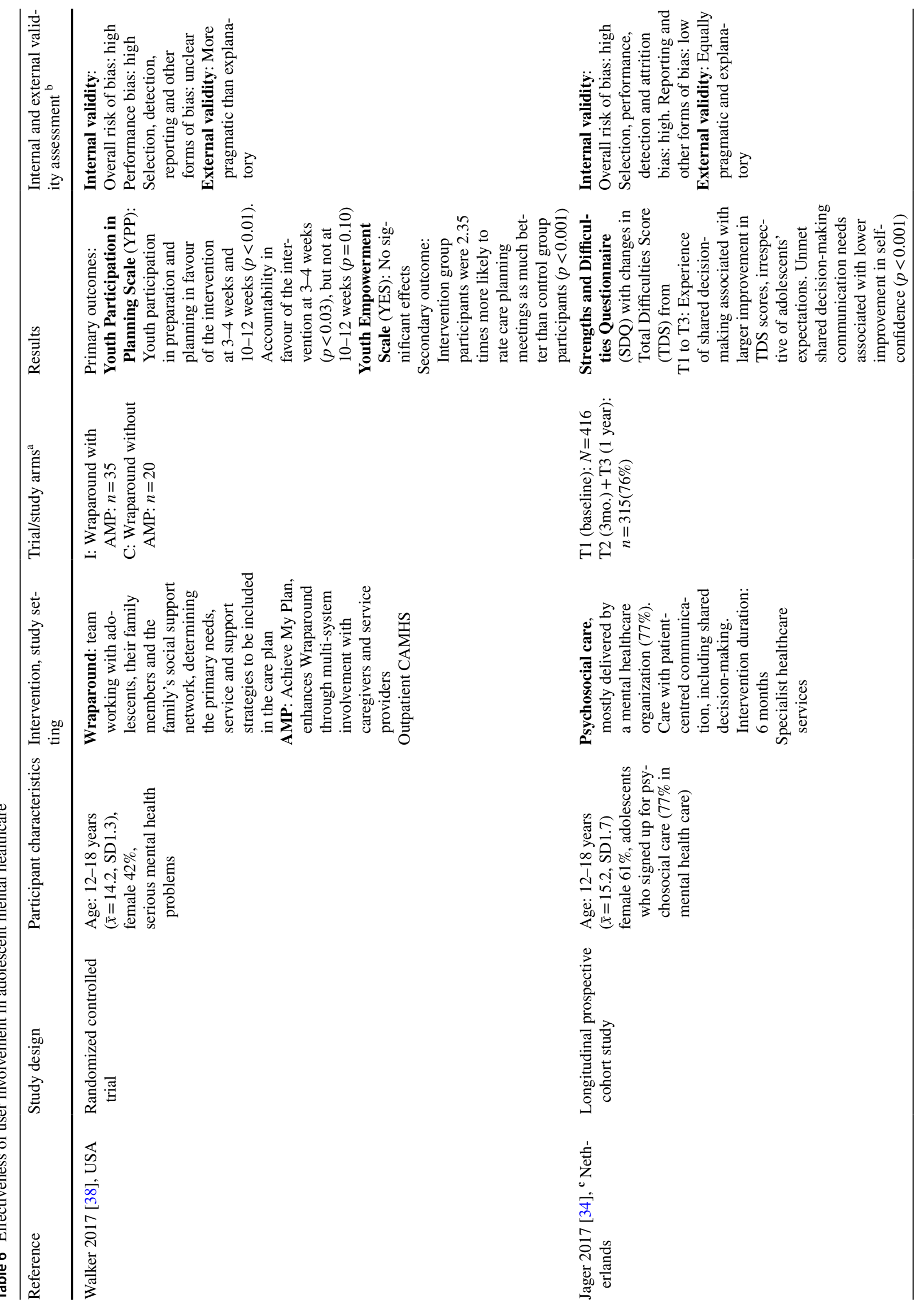




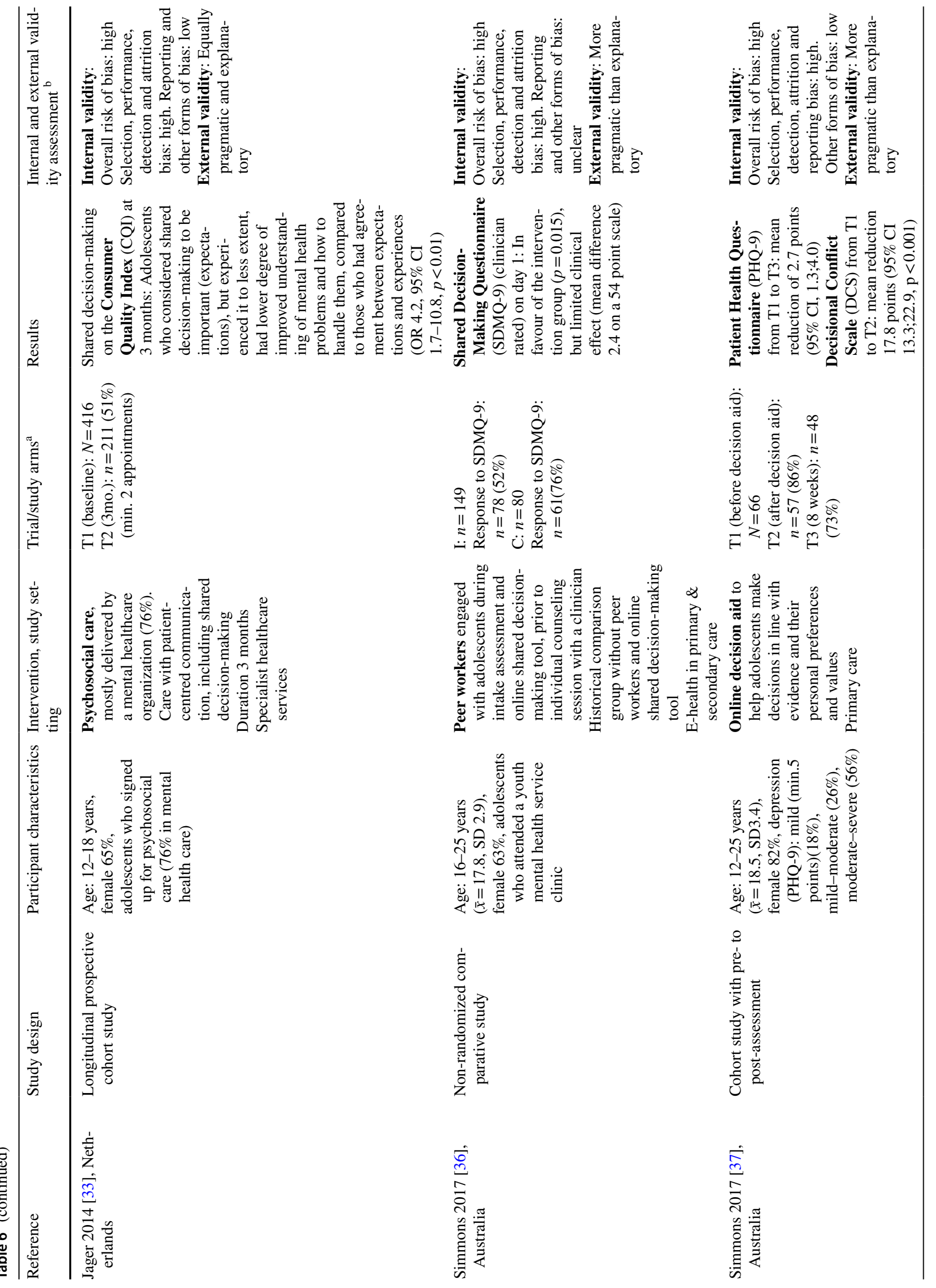




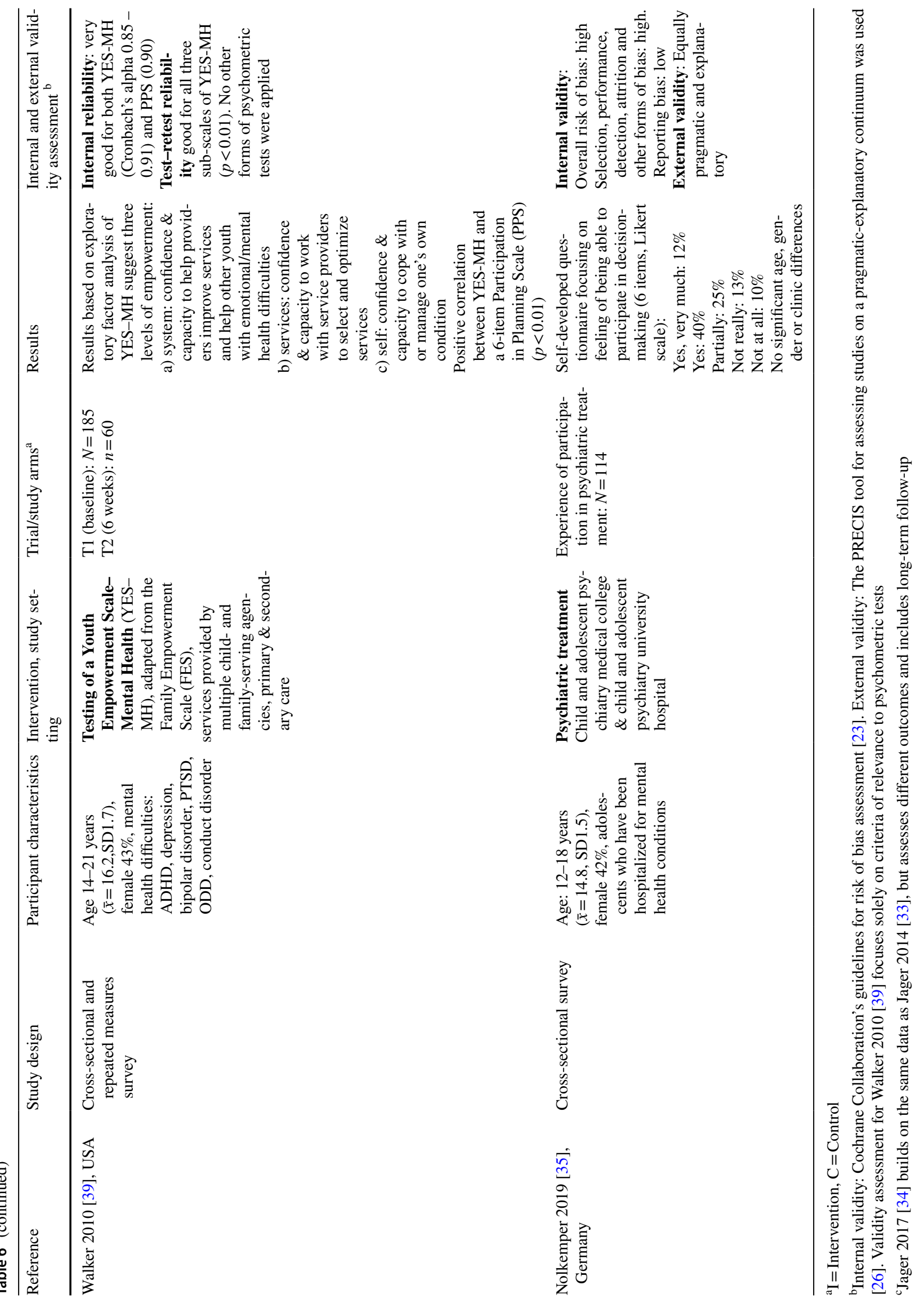




\section{User involvement at the individual level}

The thematic synthesis of qualitative studies reporting on user involvement at the individual level resulted in three themes reported below: unilateral clinician control versus collaborative relationship; capacity and support for active involvement; and the right to be involved.

\section{Unilateral clinician control versus collaborative relationship}

Adolescents' involvement could be described as a dichotomy between unilateral control and collaborative relationship. Although a continuum of involvement could be envisaged, most study participants' descriptions suggested that clinical practice involved either health personnel being in control of adolescents' treatment and clinical decisionmaking, or adolescents becoming extensively involved in their own treatment and shared decision-making processes.

Health personnel's unilateral control was found in several studies where adolescents described lack of control with limited possibilities to voice their opinion, limited treatment choices and limited involvement in decisionmaking processes [40-47]. Adolescents reported that health personnel exerted pressure and made decisions. This was illustrated by adolescents reporting that they did not feel heard [40, 42], feeling left out from meetings, being interrupted, ignored or not asked for their opinions; and pressured or forced to comply with health personnel's decisions to attend meeting sessions, engage in uninteresting activities and to take medication [40, 43-47]. A perception of unilateral control could also result from receiving too little information about their health and treatment $[42,45]$. Adolescents were reluctant to voice their opinions as they were only encouraged to express their views when they were consistent with health personnel's perspectives and expressed in what was perceived to be an acceptable manner and at an appropriate time [40, 42]. Unilateral control could result when adolescents felt activities were not individually adapted, which prevented their participation [45]. Some health personnel were sceptical of the idea of handing over control to adolescents, whereas others were opposed to controlling and enforcing compliance of their young patients [43].

Other health personnel and adolescents described a collaborative therapeutic relationship throughout the entire treatment process $[43,48]$. Collaborative relationships provided a framework that facilitated adolescents' involvement. Key features of the framework included a good adolescent-practitioner relationship, open communication, and shared decision-making processes. As part of a collaborative relationship, health personnel offered adolescents contextappropriate choices, and regularly checked to what extent they wanted to be involved in decision-making processes. A good practitioner-adolescent relationship was essential as part of building trust [43-45, 49] and was characterized by open communication where health personnel shared their knowledge as professionals, as well as carefully listened to adolescents' own experiences [42, 49, 50]. Adolescents could share their experiences with the use of medication and other aspects, which could help provide treatment options that were suitable for the individual adolescent [50]. Other examples of active collaboration included adolescents choosing their case manager, opting in or out of group participation, and engaging in various forms of treatment. The collaborative relationship, which included adolescents being offered choices in matters that affected their health care [43], contributed to shared decision-making processes [42-45, 49-52].

A collaborative relationship contributed to adolescents becoming more actively engaged in their treatment. The opposite, being left out of meetings, interrupted, ignored or not asked for input [45], or that health personnel exerted pressure and made unilateral decisions, contributed to distress and reducing their willingness to be involved in their treatment [40, 42-45, 47]. Not being involved in implementation of plans contributed to passive compliance and disengagement from the therapeutic process [53]. In a collaborative relationship where trust was established and adolescents received sufficient information, adolescents' active participation in their therapy was facilitated [42-45, 49, 50, 54]. Adolescents' involvement was associated with higher treatment attendance rates [54] and continuation of treatment; as opposed to treatment drop-out [44, 54]. Receiving enough information and support was associated with identifying treatment goals, self-care activities, and areas of decisional conflict [50]; practising ways to share information with health personnel [50]; and making informed choices for their healthcare [42].

\section{Capacity and support for active involvement}

Across all study participants, capacity and support were experienced as key to adolescents' involvement with different experiences and nuances conveyed among them. Capacity was described through adolescents' ability to be involved and share their personal experiences, whereas health personnel's capacity was described through available time and professional knowledge. Furthermore, practical or social support could strengthen adolescents' involvement [45, 49, 50, 54-56].

The different studies provided conflicting evidence between and within adolescents themselves, caregivers, and healthcare staff on adolescents' capacity to be actively involved in their healthcare [42, 43, 49, 53, 57]. Some health personnel considered adolescents' young age, immaturity, 
symptoms or diagnoses, and lack of interest, to be potential barriers to involving them in their treatment and care in general, and in decision-making processes in particular [42, 43]. Moreover, other health personnel thought it was challenging to judge adolescents' level of understanding due to medication effects [43]. Some suggested adolescents were not interested in attending and contributing to meetings [43], or were too depressed or lethargic to be actively involved in their treatment [49]. Contrary to these views, other health personnel [43] and adolescents themselves [53, 57] said they were interested in and motivated to be involved in decisions affecting their treatment. They wanted to be heard, and they had clear ideas about their care and the capacity to make sound judgements about it.

Health personnel's capacity was questioned by adolescents. They reported that staff members were overwhelmed by their workload, thereby serving as a barrier to involvement of adolescents in their care [45, 57]. Adolescents' involvement in treatment decision-making depended on the information they were provided by health personnel, which in turn was dependent on their professional competence about for example medication options, expected outcomes, side-effects and possible treatment choices [50].

Being informed about their health and treatment options was a typical form of practical support for adolescents' active involvement $[45,49,50,54]$. Too little information resulted in adolescents feeling lack of support through insufficient control and lack of motivation to be involved in their treatment $[42,45]$. In order for information to be of help, it had to be relevant to adolescents [43]. Practical support could also involve enabling adolescents to come to consultations and limited transport options could reduce their possibilities to be more actively involved in appointments and activities [57]. However, adolescents also needed social support, for example by being heard, offered contextappropriate choices, and encouraged to actively participate in decision-making processes [43, 45, 49, 50, 54].

Although several studies suggested that adolescents wanted to be actively involved in decision-making processes, adolescents also expressed awareness of the challenges associated with being in a transitional phase, moving from childhood to adult life [42]. They sought support from others as part of the process, in particular by seeking information and guidance from parents and health personnel to help them make decisions [42, 49, 50, 52, 54]. According to adolescents, their parents and health personnel could support adolescents by sharing their professional knowledge and to provide them with tools such as shared decision worksheets [50], to help them make choices for their healthcare [52]. Adolescents were of the opinion that through a thorough exploration of their experiences, relationships, support networks, and views, health personnel would be in a better position to provide treatment options that were acceptable to adolescents and compatible with their cultural background $[51,52]$. Health personnel could for example combine this with their professional knowledge to suggest treatment options other than medication [51].

\section{The right to be involved}

A prerequisite for adolescents' involvement in their treatment was a basic understanding of their inherent right to be involved [41-43, 49, 50, 53, 57]. Regardless of their age, adolescents wanted to be heard, their autonomy to be respected, and to be involved in decisions affecting their treatment, health, and wellbeing [41, 43, 48, 49, 53, 54, 57]. Although the degree of need for involvement varied between adolescents, they actively sought opportunities to be involved in decision-making processes [53], and expressed a wish to maintain some control through involvement in the patient-practitioner relationship [42]. They considered this to be essential to maintain their sense of autonomy [42, 49, 54]. Involvement could include for example decisions about their treatment plans $[41,43]$; choice and change of therapist $[43,48,54]$; the time, length and frequency of treatment sessions $[48,54]$ and text message feedback solutions to express such wishes [58]; which family members who could attend meetings [48]; and the right to refuse health personnel's proposals [54], including the use of medication [48]. Health personnel mostly shared adolescents' views of their fundamental right to express their opinion, and they considered it a helpful contribution to treatment, although some healthcare personnel were sceptical about giving adolescents control of decisions related to their treatment $[42,43]$.

\section{User involvement at the organizational level}

The thematic synthesis of qualitative studies reporting on user involvement at the organizational level resulted in two themes reported below: involvement outcomes relevant to adolescents' needs; and conditions for optimal involvement.

\section{Involvement outcomes relevant to adolescents' needs}

Involving adolescents at the organizational level should contribute to outcomes relevant to adolescents' needs, seen from the perspectives of adolescents, caregivers, and health personnel. In general, participants expressed that adolescents' involvement contributed to developing and improving mental health services or that it had the potential to do so [40, 56, 59-63]. More specifically, this included the development and use of terminology and models for mental health and participation relevant to adolescents $[56,59,62]$. The design and contents of interventions and psychoeducational resources should reflect adolescents' experiences and needs 
[63]. Allowing adolescents the opportunity to influence the design and implementation of treatment programmes and interventions to improve treatment outcomes helped strengthen the relevance, appropriateness, and acceptability of the treatment [60-63]. Adolescents' involvement did also contribute to change the treatment environment so that it was better adapted to adolescents' needs, for example to make conference rooms less formal [40]. Adolescents' perspectives did also contribute to improve the content of health personnel's training, and the relevance and quality of the services [60].

Adolescent consultants contributed to empower other adolescents with mental health challenges to take charge of their recovery through, e.g. educational or one-on-one support. They helped other adolescents and parents to identify their goals, self-care activities, and areas of decisional conflict [50], as well as to negotiate the patient-practitioner relationship when adolescents did not get along with their counsellor [55]. Implications for adolescents who participated as consultants could potentially also support their sense of autonomy and self-efficacy and empower them to take charge of their own recovery. Moreover, they could gain work experience, build professional and social skills, and expand their networks within the context of a safe environment with proper support [55, 59].

\section{Conditions for optimal involvement}

Conditions for adolescents' optimal involvement at the organizational level reported across study participants included openness to adolescents' viewpoints and understandings, clarity of roles, information provision, autonomy, skills training, backgrounds and personal experiences, diversity, and formal recognition of efforts to involve adolescents $[45,50,53,55,56,59,61,63]$.

In order to involve adolescents at the organizational level, professionals needed to be open to adolescents' viewpoints and understandings of mental health [56], and clear definition and clarity of roles should be agreed and described to understand the boundaries and limitations of adolescents' involvement [50, 59, 61].

Adolescents also thought involvement could be optimized by information provided for them about existing services and projects which they could be involved in $[45,50]$. By being given the freedom to identify and make decisions about projects they cared about and could run themselves $[45,50,56$, 61], adolescents could make autonomous decisions about whether and the extent to which they wanted to be involved [50].

Skills training supported optimal involvement of adolescents at the organizational level. Such training could introduce roles, tools, and methods for shared decision-making processes [50, 59]. Tools could for example include methods to formalize and facilitate shared decision-making while still allowing flexibility for the individual needs of adolescents and parents [50].

Adolescents having personal experiences with the mental health services could optimize their involvement at the organizational level, particularly if they worked directly with other adolescents as peer consultants, so that they could better understand their concerns and needs $[59,61]$. Adolescents who had received hospital treatment for serious mental illnesses had clear ideas concerning rules, regulations, and treatment and could make sound judgments about such treatment [53]. Furthermore, adolescents with diverse backgrounds and those from "disadvantaged" backgrounds would strengthen the diversity in perspectives and increase the likelihood that changes to services would be relevant to adolescents of, e.g. ethnic minority backgrounds [55, 59].

Formal recognition of adolescents' contribution as consultants was to provide payment as employees rather than involving them as volunteers, and to enable them to work both independently and be involved in group activities [59]. Adolescents pointed out that leaders could recognize staff who encouraged user involvement, organized workshops, and discussed their experiences, as well as communicate the benefits of user involvement within their clinics [50].

\section{Effectiveness of user involvement}

A narrative report of results of individual studies on the effectiveness of user involvement is presented in text and in tabular form (Table 6). The articles reporting on individual studies are presented according to the level of evidence associated with their research design (from randomized controlled trials to cross-sectional surveys). No synthesis of data is presented due to heterogeneity of interventions and outcomes.

\section{User involvement at the individual level}

Out of six identified articles, three assessed the effectiveness of additional support to facilitate adolescents' involvement in their own care [36-38]; one assessed the effectiveness of shared decision-making on adolescents' ability to handle mental health problems in the short term [33] and their overall strengths, difficulties and self-confidence in the longer term [34]; and one reported the prevalence of adolescents' participation in decision-making [35].

The results of a randomized controlled trial suggest that additional support provided by a team working with adolescents with severe mental health problems, their family and social support network in developing a care plan, may increase youth participation in treatment planning, both in the short (3-4 weeks) and longer term (10-12 weeks) $(p<0.01)$ [38]. These adolescents were more than twice as 
likely to positively rate care planning meetings, compared to those in the control group $(p<0.001)$.

A non-randomized controlled study that took place in a youth mental health service clinic found a significant effect, measured using the Shared Decision-Making Questionnaire (SDMQ-9) $(p=0.015)$, of a combination of peer workers engaged with adolescents at intake assessment together with an online shared decision-making tool prior to counselling sessions, compared to a historical comparison group [36]. The results did, however, only suggest a small clinical effect.

Results of a cohort study suggested that adolescents who had higher expectations but poorer experiences of shared decisions-making in psychosocial care had lower degrees of understanding of and ability to handle mental health problems at 3 months, compared to adolescents whose experiences corresponded with their expectations (OR 4.2, 95\% CI $1.7-10.8, p<0.01$ ) [33]. In the long-term follow-up at one year, shared decision-making was associated with significant changes in adolescents' Total Difficulties Score (TDS), measured using the Strengths and Difficulties Questionnaire (SDQ) [34]. Although results were then irrespective of adolescents' expectations, improvement in self-confidence was lower when communication needs were not met $(p<0.001)$.

An online aid aimed at supporting adolescents with mild to severe depression in making decisions in line with their values and preferences, as well as in line with the existing research evidence, was tested in a cohort study from baseline to eight weeks [37]. At 8 weeks, results showed a statistically significant reduction in depression (PHQ-9) scores, although the clinical importance of this was uncertain (mean change 2.7 points, $95 \%$ CI, 1.3;4.0). Significant improvements were also found on the Decisional Conflict Scale (DCS) from before to after use of the decision aid (mean change 17.8 points, 95\% CI 13.3;22.9).

Results of a cross-sectional survey suggested that over half of adolescents who had been hospitalized for mental health conditions felt they were able to participate in decision-making processes, whereas one quarter felt they could participate partially and one quarter not at all [35].

\section{User involvement at the organizational level}

A cross-sectional and repeated measures survey reported on results of testing a Youth Empowerment Scale-Mental Health (YES-MH) for adolescents with various mental health difficulties [39]. The survey measured adolescents' participation in team-based services and treatment planning for mental health services. Results of a factor analysis suggested empowerment of adolescents through their confidence and capacity to work with service providers to select and optimize services; to help providers improve services; and to help other youth with mental health difficulties.

\section{Safety associated with user involvement}

No study aimed to report on the safety associated with user involvement in adolescents' mental healthcare. A few studies did however report on issues that potentially could influence the safety of adolescents' mental healthcare. Examples included a qualitative study where involvement of adolescents in decision-making was thought to be a potential threat to their safety by some health personnel [43]. Their arguments did, however, not pertain to the individual youths' capability or competence to participate in decision-making, but could be understood as exercising undue professional power as they considered adolescents not to be competent in making decisions for their mental healthcare irrespective of their arguments, state of health or level of maturity. In a second qualitative study, some staff expressed concerns about risks associated with involvement of adolescent consultants. For example, the experience of being a consultant was thought by some staff to potentially be overwhelming to adolescents and could serve as a barrier to their own recovery [59]. Healthcare personnel thought these adolescents could also misunderstand conversations between staff and thereby breach confidentiality.

\section{Discussion}

This systematic review of user involvement in adolescents' mental healthcare demonstrates that the current literature is dispersed and fragmented. There is weak evidence for the effectiveness of user involvement using quantitative research designs, while there is more evidence for the experiences with user involvement using qualitative research methods. There is hardly any evidence addressing safety issues associated with user involvement. User involvement at the individual level is more often reported in studies than user involvement at the organizational level.

The results of the review leave little doubt that adolescents want to be involved in decisions affecting their mental healthcare, thereby confirming earlier findings [e.g. 14]. However, user involvement of adolescents in mental healthcare at the individual level takes many forms and with different experiences ranging from "just" being heard about their opinion to being involved in decision-making processes. In a recent systematic review, factors influencing person-centred care were examined, recommending greater focus on the role of relationships, service information, and support and training for professionals [64]. These factors are supported by the current review results, and in particular by the clear evidence of positive experiences related to collaborative relationships.

The effectiveness of adolescents' involvement at the individual level is still not established in the research literature besides preliminary findings in a few interventional studies 
showing evidence for certain tools related to support care planning meetings, intake assessment, and shared decisionmaking [36-38]. Some evidence was also found suggesting that involvement in decision-making could potentially contribute to improved mental health outcomes [33, 34]. These results should, however, be interpreted with caution, both due to the limited number of identified studies and due to high risk of bias. Results of another systematic review suggested that interventions considering barriers at several levels (individual, family, community, organization) were effective in supporting adolescents' engagement in mental healthcare [65]. However, this review examined attendance, rather than user involvement.

User involvement of adolescents in mental healthcare at the organizational level is less commonly reported in the literature but shares similarities with the individual level concerning the conditions of information, openness, and support structures. Distinct organizational level issues were related to the need for skills training, clarity of roles and the inclusion of adolescents of different backgrounds and with different experiences. The preliminary evidence suggests such involvement at the organizational level could potentially contribute to development of outcomes of relevance to adolescents' needs [39].

The paucity of research evidence assessing safety issues associated with user involvement in adolescents' mental healthcare is striking. However, the World Health Organization suggests that involvement of patients may be fundamental to improve patient safety [12]. Our review found a lack of literature exploring safety issues of how adolescents may be involved to improve patient safety. The sparse literature suggests that professionals doubt adolescents' capacity to be involved due to age and severity of symptoms, in particular during a mental health crisis [64]. We identified a single study [43] indicating that organizational culture and paternalistic approaches may affect professionals' perception of adolescents' involvement as a safety issue. It is unclear why there is such a paucity of safety research focusing on user involvement in adolescents' mental healthcare given the importance of patient safety for example for adolescents who self-harm, who have suicidal thoughts or plans, or eating disorders. Practitioners' concerns about potential adverse events and deterioration of adolescents' mental health might explain their reluctance to involve them in decision-making processes. This could, e.g. include adolescents right to refuse medication. However, an opposing argument may be that more active involvement of adolescents in their mental healthcare could strengthen their trust in practitioners and therapies offered and to increase treatment compliance. This would also be more in line with a recovery-oriented approach supporting adolescents' active engagement and health-promoting involvement. Where involvement in decision-making could pose a potential threat to adolescents' safety, alternative approaches to involving adolescents could be suggested, e.g. to inform about and discuss the reasons for not giving them decision-making power. More research is needed to test hypotheses and to map safety issues and barriers to user involvement both at the individual and organizational level. Additional research is further needed to determine how to tailor user involvement so that adolescents with variable capacities can safely participate in their treatment.

\section{Strengths and limitations}

It cannot be ruled out that the applied review procedures contributed to overseeing relevant studies, as there seems to be no standardized search terminology associated with the field of adolescents' involvement. This is suggested as half of the identified literature was found through a single source and no single database identified more than half of the studies. The use of search terminology in other languages might have helped to identify more articles published in the non-English literature. However, the review considerably expands past limited research-based knowledge about involvement in adolescents' mental healthcare [e.g. 15], and we consider it a strength to have used a substantial number of databases, a broad range of search terms, and that two researchers carried out all parts of the search processes.

The age limitation (13-18 years) may have resulted in exclusion of studies focusing on young adults that could be of relevance to teenagers. However, the applied age range was selected in order to specifically focus on an under-investigated group of adolescents who are in a phase in life where they may have varying degrees of decision-making rights depending on national legislation and regulation.

The heterogeneity of identified studies resulting from different research designs and different outcomes is not surprising, due to the use of wide inclusion criteria. However, the limited amount of identified literature precluded development of recommendations for any sub-groups of adolescents, for example according to ethnicity or diagnostic groups. Moreover, no conclusions can be drawn about safety issues associated with user involvement, as hardly any research addressed such issues. Nevertheless, a strength of the systematic review is that the results of the meta-synthesis provide insight into the experiences of user involvement in adolescents' mental healthcare. Furthermore, adolescent coresearchers were involved in the analytic process in order to also include their perspectives.

\section{Recommendations}

Mental healthcare services should facilitate user involvement to promote treatment attendance and adherence. Guidelines for strengthening the collaborative practitioner-adolescent relationship should be developed with input from 
adolescents, including those with ethnic and other minority backgrounds, as well as healthcare practitioners. Guidelines should include suggestions for questions for reflection as part of the patient-practitioner relationship to strengthen adolescents' active involvement in their own healthcare. Issues to be included could be adolescents' values and preferences; the extent and ways in which they want to be involved in their own treatment; the persons who may represent them when they do not want to be actively involved; adolescents' treatment preferences in the event they are only to a limited extent able to participate in decision-making (e.g. in psychotic phases); the means and purposes of their involvement in decision-making processes. Facilitators to user involvement beyond capacity and support should be further explored. We suggest involving adolescents with diverse backgrounds at an organizational level when developing and improving services to strengthen the relevance of mental health services.

Although involvement of adolescents in their mental healthcare should be considered a human right and also a legal obligation, there is considerable need for more research-based knowledge about the best ways in which adolescents want to and can be involved in their mental healthcare. Research should assess the effectiveness of user involvement in adolescents' mental healthcare, using outcomes of clinical relevance and of relevance to adolescents themselves. Safety research should particularly address issues of involvement for at-risk groups, to identify the extent and ways in which these adolescents can best be involved in decisions affecting their mental healthcare. Further research is also needed to explore how user involvement can best be adapted to different sub-groups, for example for various ethnic and minority groups. Moreover, further knowledge is needed on how to strengthen the facilitators and limit the barriers to user involvement, including support and training for healthcare personnel.

\section{Conclusion}

By systematically reviewing the literature, we have established the current knowledge evidence on the experiences with, the effectiveness of, and the safety associated with user involvement in adolescents' mental healthcare. Results identify a variety of experiences at the individual level related to the continuum between unilateral control exerted by clinicians and a collaborative practitioner-adolescent relationship; the key of capacity and support for adolescents' involvement; and the prerequisite of a basic understanding of adolescents' inherent right to be involved. Less experiences are identified related to the organizational level, yet the need to ensure relevant outcomes of involvement for adolescents was established as a vital parameter, as well as a set of conditions for optimal involvement. The effectiveness of user involvement is less clear in the current literature, yet some preliminary evidence is established related to interventions such as support for care planning meetings, intake assessment, and shared decision-making. Evidence for potential safety issues associated with adolescents' user involvement is currently not established in the research literature. The results of the reported literature review warrant future research within the areas of organizational level involvement of adolescents, the development and effectiveness of different measures for adolescents' user involvement, and how involvement of adolescents may influence patient safety.

Supplementary Information The online version contains supplementary material available at https://doi.org/10.1007/s00787-021-01818-2.

Acknowledgements We thank Grete Mortensen for her support in developing an electronic search strategy. Furthermore, we thank the authors we contacted for their suggestions for additional research literature.

Author contributions PV, SEB, NEC, JRG, SHB, MS and KAA contributed to developing the search and assessment strategies, the development of selection criteria, and data extraction criteria. PV and SB conducted literature search and screened titles and abstracts. PV, SEB, SHB, AS, MS and KAA screened full text and carried out data extraction. JRG and NEC provided their perspectives on inclusion/exclusion of articles where there was not a unanimous decision among the other authors. PV, SEB and KAA conducted the data synthesis. NEC and JRG contributed to the interpretation. PV and SEB drafted the manuscript; KA reviewed and edited the manuscript. All authors commented on draft versions and approved the final manuscript.

Funding Open access funding provided by University Of Stavanger.

Availability of data and materials The research materials can be accessed by contacting the corresponding authors.

\section{Declarations}

Competing interests None.

Open Access This article is licensed under a Creative Commons Attribution 4.0 International License, which permits use, sharing, adaptation, distribution and reproduction in any medium or format, as long as you give appropriate credit to the original author(s) and the source, provide a link to the Creative Commons licence, and indicate if changes were made. The images or other third party material in this article are included in the article's Creative Commons licence, unless indicated otherwise in a credit line to the material. If material is not included in the article's Creative Commons licence and your intended use is not permitted by statutory regulation or exceeds the permitted use, you will need to obtain permission directly from the copyright holder. To view a copy of this licence, visit http://creativecommons.org/licenses/by/4.0/. 


\section{References}

1. Clayborne ZM, Varin M, Colman I (2019) Systematic review and meta-analysis: adolescent depression and long-term psychosocial outcomes. J Am Acad Child Adolesc Psychiatry 58(1):72-79. https://doi.org/10.1016/j.jaac.2018.07.896

2. Kessler RC, McLaughlin KA, Green JG, Gruber MJ, Sampson NA, Zaslavsky AM, Aguilar-Gaxiola S, Alhamzawi AO, Alonso J, Angermeyer M, Benjet C, Bromet E, Chatterji S, de Girolamo G, Demyttenaere K, Fayyad J, Florescu S, Gal G, Gureje O, Haro JM, Hu CY, Karam EG, Kawakami N, Lee S, Lépine JP, Ormel J, Posada-Villa J, Sagar R, Tsang A, Ustün TB, Vassilev S, Viana MC, Williams DR (2010) Childhood adversities and adult psychopathology in the WHO World Mental Health Surveys. Br J Psychiatry 197(5):378-385. https://doi.org/10.1192/bjp.bp.110. 080499

3. McPherson KE, Kerr S, McGee E, Morgan A, Cheater FM, McLean J, Egan J (2014) The association between social capital and mental health and behavioural problems in children and adolescents: an integrative systematic review. MC Psychol 2(1):7. https://doi.org/10.1186/2050-7283-2-7

4. Polanczyk GV, Salum GA, Sugaya LS, Caye A, Rohde LA (2015) Annual research review: a meta-analysis of the worldwide prevalence of mental disorders in children and adolescents. J Child Psychol Psychiatry 56(3):345-365. https://doi.org/10.1111/jcpp. 12381

5. Kaushik A, Kostaki E, Kyriakopoulos M (2016) The stigma of mental illness in children and adolescents: a systematic review. Psychiatry Res 243:469-494. https://doi.org/10.1016/j.psychres. 2016.04.042

6. Kapp C, Perlini T, Jeanneret T, Stéphan P, Rojas-Urrego A, Macias M, Halfon O, Holzer L, Urben S (2017) Identifying the determinants of perceived quality in outpatient child and adolescent mental health services from the perspectives of parents and patients. Eur Child Adolesc Psychiatry 26(10):1269-1277. https:// doi.org/10.1007/s00787-017-0985-Z

7. Jones PB (2013) Adult mental health disorders and their age at onset. Br J Psychiatry Suppl 54:s5-10. https://doi.org/10.1192/bjp. bp.112.119164

8. United Nations (1989) Convention on the rights of the child. Adopted and opened for signature, ratification and accession by General Assembly resolution 44/25 of 20 November 1989, entry into force 2 September 1990, in accordance with article 49.

9. European Union Agency for Fundamental Rights and Council of Europe (2015) Handbook on European law relating to the rights of the child, June. ISBN 978-92-9491-543-6

10. Lansdown G (2011) Every child's right to be heard. A resource guide on the UN Committee on the Rights of the Child, general comment no. 12. Save the Children and UNICEF

11. Haldane V, Chuah FLH, Srivastava A, Singh SR, KohGCH SCK, Legido-Quigley H (2019) Community participation in health services development, implementation, and evaluation: a systematic review of empowerment, health, community, and process outcomes. PLoS ONE 14(5):e0216112. https://doi.org/10.1371/ journal.pone. 0216112

12. World Health Organization (2016) Patient Engagement: Technical Series on Safer Primary Care. Geneva: World Health Organization. Licence: CC BY-NC-SA 3.0 IGO.

13. Storm M, Hausken K, Knudsen K (2011) Inpatient service providers' perspectives on service user involvement in Norwegian community mental health centres. Int J Soc Psychiatry 57(6):551-563. https://doi.org/10.1177/0020764010371270

14. Dogra N (2005) What do children and young people want from mental health services? Curr Opin Psychiatry 18(4):370-373. https://doi.org/10.1097/01.yco.0000172053.17660.61
15. Feenstra B, Boland L, Lawson ML, Harrison D, Kryworuchko J, Leblanc M, Stacey D (2014) Interventions to support children's engagement in health-related decisions: a systematic review. BMC Pediatr 14:109. https://doi.org/10.1186/1471-2431-14-109

16. Cheng H, Hayes D, Edbrooke-Childs J, Martin K, Chapman L, Wolpert M (2017) What approaches for promoting shared decision-making are used in child mental health? A scoping review. Clin Psychol Psychother 24:O1495-O1511. https://doi.org/10. 1002/cpp. 2106

17. Liverpool S, Pereira B, Hayes D, Wolpert M, Edbrooke-Childs J (2020) A scoping review and assessment of essential elements of shared decision-making of parent-involved interventions in child and adolescent mental health. Eur Child Adolesc Psychiatry. https://doi.org/10.1007/s00787-020-01530-7

18. Abrines-Jaume N, Midgley N, Hopkins K, Hoffman J, Martin K, Law D, Wolpert M (2014) A qualitative analysis of implementing shared decision making in child and adolescent mental health services in the United Kingdom: Stages and facilitators. Clin Child Psychol Psychiatry 21:1. https://doi.org/10.1177/1359104547596

19. Viksveen P, Bjønness SE, Berg SH, Cardenas NE, Game JR, Aase K, Storm M (2017) User involvement in adolescents' mental healthcare: protocol for a systematic review. BMJ Open 7(12):e018800. https://doi.org/10.1136/bmjopen-2017-018800

20. Critical Appraisal Skills Programme (2018). CASP Qualitative Checklist. https://casp-uk.net/wp-content/uploads/2018/03/CASPQualitative-Checklist-2018_fillable_form.pdf Accessed 23 Dec 2020

21. Cochrane Consumers and Communication (2016) Data extraction template for included studies. Form version/date, version 1.8, updated 29 November 2016. https://cccrg.cochrane.org/authorresources Accessed 23.12.2020

22. von Elm E, Altman DG, Egger M, Pocock SJ, Gøtzsche PC, Vandenbroucke JP, Initiative STROBE (2014) The Strengthening the Reporting of Observational Studies in Epidemiology (STROBE) Statement: guidelines for reporting observational studies. Int J Surg 12(12):1495-1499. https://doi.org/10.1016/j.ijsu.2014.07. 013

23. Higgins JPT, Altman DG, Gøtzsche PC, Jüni P, Moher D, Oxman AD, Savović J, Schulz KF, Weeks L, Sterne JAC (2011) The Cochrane Collaboration's tool for assessing risk of bias in randomised trials. BMJ 343:d5928. https://doi.org/10.1136/bmj. d5928

24. Reeves BC, Deeks JJ, Higgins JPT, Wells G (2011) Chapter 13: Including non-randomized studies. In: Higgins JPT, Green S (editors), Cochrane Handbook for Systematic Reviews of Interventions Version 5.1.0 (updated March 2011). The Cochrane Collaboration, 2011. www.handbook.cochrane.org (last visited 05.05.2017)

25. Moher D, Shamseer L, Clarke M, Ghersi D, Liberati A, Petticrew M, Shekelle P, Stewart LA, PRISMA-P Group (2015) Preferred reporting items for systematic review and meta-analysis protocols (PRISMA-P) 2015 statement. Syst Rev 4(1):1. https://doi.org/10. 1186/2046-4053-4-1

26. Thorpe KE, Zwarenstein M, Oxman AD, Treweek S, Furberg CD, Altman DG, Tunis S, Bergel E, Harvey I, Magid DJ, Chalkidou K (2009) A pragmatic-explanatory continuum indicator summary (PRECIS): a tool to help trial designers. J Clin Epidemiol 62(5):464-475. https://doi.org/10.1016/j.jclinepi.2008.12.011

27. Horntvedt MET, Nordsteien A, Fermann T, Severinsson E (2018) Strategies for teaching evidence-based practice in nursing education: a thematic literature review. BMC Med Educ 18(1):172. https://doi.org/10.1186/s12909-018-1278-z

28. Moher D, Liberati A, Tetzlaff J, Altman DG; PRISMA Group (2009) Preferred reporting items for systematic reviews and metaanalyses: the PRISMA statement. BMJ 339:b2535. https://doi.org/ 10.1136/bmj.b2535 
29. Schulz KF, Altman DG, Moher D; CONSORT Group (2010) CONSORT 2010 statement: updated guidelines for reporting parallel group randomised trials. BMJ 340:c332. https://doi.org/ 10.1136/bmj.c332

30. Lucas PJ, Arai L, Baird LC, Roberts HM (2007) Worked examples of alternative methods for the synthesis of qualitative and quantitative research in systematic reviews. BMC Med Res Meth 7:4. https://doi.org/10.1186/1471-2288-7-4

31. Thomas J, Harden A (2008) Methods for the thematic synthesis of qualitative research in systematic reviews. BMC Med Res Methodol 8:45. https://doi.org/10.1186/1471-2288-8-45

32. Thorne S, Jensen L, Kearney MH, Noblit G, Sandelowski M (2004) Qualitative metasynthesis: reflections on methodological orientation and ideological agenda. Qual Health Res 14(10):13421365. https://doi.org/10.1177/1049732304269888

33. Jager M, Reijneveld SA, Metselaar J, Knorth EJ, De Winter AF (2014) Discrepancies between adolescents' attributed relevance and experiences regarding communication are associated with poorer client participation and learning processes in psychosocial care. Patient Educ Couns 97(3):332-338. https://doi.org/10. 1016/j.pec.2014.08.020

34. Jager M, Reijneveld SA, Almansa J, Metselaar J, Knorth EJ, De Winter AF (2017) Less reduction of psychosocial problems among adolescents with unmet communication needs. Eur Child Adolesc Psychiatry 26(4):403-412. https://doi.org/10.1007/ s00787-016-0901-y

35. Nolkemper D, Wiggert N, Müller S, Fegert JM, Kölch M (2019) Participation and Information in Child and Youth Psychiatry. Prax Kinderpsychol Kinderpsychiatr 68(4):271-285. https://doi.org/10. 13109/prkk.2019.68.4.271

36. Simmons MB, Batchelor S, Dimopoulos-Bick T, Howe D (2017) The Choice Project: peer workers promoting shared decision making at a youth mental health service. Psychiatr Serv 68(8):764 770. https://doi.org/10.1176/appi.ps.201600388

37. Simmons MB, Elmes A, MCKenzie JE, Trevena L, Hetrick SE, (2017) Right choice, right time: evaluation of an online decision aid for youth depression. Health Expect 20:714-723

38. Walker JS, Seibel CL, Jackson S (2017) Increasing youths' participation in team-based treatment planning: the achieve my plan enhancement for Wraparound. J Child Fam Stud 26:2090-2100. https://doi.org/10.1007/s10826-017-0738-0

39. Walker JS, Thorne EK, Powers LE, Gaonkar R (2010) Development of a scale to measure the empowerment of youth consumers of mental health services. Behav Disord 18(1):51-59. https://doi. org/10.1177/1063426609337388

40. Boydell KM, Volpe T, Pignatiello A (2010) A qualitative study of young people's perspectives on receiving psychiatric services via televideo. J Can Acad Child Adolesc Psychiatry 19(1):5-11

41. Coyne I, McNamara N, Healy M, Gower C, Sarkar M, McNicholas F (2015) Adolescents' and parents' views of Child and Adolescent Mental Health Services (CAMHS) in Ireland. J Psychiatr Ment Health Nurs 22(8):561-569. https://doi.org/10.1111/jpm. 12215

42. LeFrancois BA (2007) Children's participation rights: Voicing opinions in inpatient care. Child Adolesc Mental Health 12(2):9497. https://doi.org/10.1111/j.1475-3588.2007.00439.x

43. LeFrancois BA (2008) "It's like mental torture": participation and mental health services. Int J Childr Rights 16:211-227. https:// doi.org/10.1163/157181808X301809

44. Oruche UM, Downs S, Holloway E, Draucker C, Aalsma M (2014) Barriers and facilitators to treatment participation by adolescents in a community mental health clinic. J Psychiatr Ment Health Nurs 21(3):241-248. https://doi.org/10.1111/jpm.12076

45. Rodarmel S (2014) Family-driven and youth-driven perspectives on engagement in school-based mental health. Dissertation Abstracts Int Sect A 74:11
46. Manning JC, Bingham V, Wood DM (2016) Establishing patientcentred outcomes for acute inpatient care of adolescents with mental health problems. J Adolesc Health 1:S59. https://doi.org/ 10.1016/j.jadohealth.2015.10.130

47. Moses T (2011) Adolescents' perspectives about brief psychiatric hospitalization: what is helpful and what is not? Psychiatr Q 82(2):121-137. https://doi.org/10.1007/s11126-010-9151-1

48. Hart A, Saunders A, Thomas H (2005) Attuned practice: a service user study of specialist child and adolescent mental health UK. Epidemiol Psichiatr Soc 14(1):22-31. https://doi.org/10.1017/ s1121189x00001895

49. Wisdom JP, Clarke GN, Green CA (2006) What teens want: barriers to seeking care for depression. Adm Policy Ment Health 33(2):133-145. https://doi.org/10.1007/s10488-006-0036-4

50. Crickard EL, O'Brien MS, Rapp CA, Holmes CL (2010) Developing a framework to support shared decision making for youth mental health medication treatment. Community Ment Health J 46(5):474-481. https://doi.org/10.1007/s10597-010-9327-z

51. Graham T, Rose D, Murray J, Ashworth M, Tylee A (2014) User-generated quality standards for youth mental health in primary care: a participatory research design using mixed methods. BMJ Qual Saf 23(10):857-866. https://doi.org/10.1136/ bmjqs-2014-002842

52. Sundar P, Todd S, Danseco E, Kelly LJ, Cunning S (2012) Toward a culturally responsive approach to child and youth mental health practice: Integrating the perspectives of service users and provider. Can J Commun Ment Health 31(1):99-113

53. Gros CP, Parr C, Wright DK, Montreuil M, Frechette J (2017) Hospital rules and regulations: the perspectives of youth receiving psychiatric care. J Child Adolesc Psychiatr Nurs 30(1):18-24. https://doi.org/10.1111/jcap.12166

54. Bjønness S (2015) Adolescents' experiences with outpatient mental health care: A qualitative study in treatment drop-out. [Norwegian.] Master Dissertation, Institute of Health, Master of Health Sciences, University of Stavanger. https://uis.brage.unit. no/uis-xmlui/handle/11250/300044 Accessed 23 Dec 2020

55. Coates D, Howe D (2014) The importance and benefits of youth participation in mental health settings from the perspective of the headspace Gosford Youth Alliance in Australia. Child Youth Serv Rev 46:294-299. https://doi.org/10.1016/j.childyouth.2014. 09.012

56. Nadeau L, Jaimes A, Johnson-Lafleur J, Rousseau C (2017) Perspectives of migrant youth, parents and clinicians on community-based mental health services: negotiating safe pathways. J Child Fam Stud 26:1936-1948. https://doi.org/10.1007/ s10826-017-0700-1

57. Block AM, Gjesfjeld CD, Greeno CG (2013) Adolescent perspectives of outpatient mental health treatment. Best Pract Ment Health 9(2):22-38

58. Ranney ML, Thorsen M, Patena JV, Cunningham RM, Boyer EW, Walton MA, Spirito A, Zatzick DF, Morrow K (2015) You need to get them where they feel it: conflicting perspectives on how to maximize the structure of text-message psychological interventions for adolescents. Proc Annu Hawaii Int Conf Syst Sci. https:// doi.org/10.1109/hicss.2015.391

59. Coates $D$, Howe $D$ (2016) Integrating a youth participation model in a youth mental health service: challenges and lessons learned. Child Youth Serv 37(3):287-300. https://doi.org/10.1080/01459 35X.2015.1119652

60. Latif A, Carter T, Rychwalska-Brown L, Wharrad H, Manning J (2017) Co-producing a digital educational programme for registered children's nurses to improve care of children and young people admitted with self-harm. J Child Health Care 21(2):191-200. https://doi.org/10.1177/1367493517697853

61. Stockburger J, Parsa-Pajouh B, de Leeuw S, Greenwood M (2005) Youth voices on prevention and intervention of youth substance 
abuse. Centre Excell Child Adolescents Spec Needs. ISBN 0-9731323-2-9

62. Thorsen MM, Patena JV, Guthrie KM, Spirito A, Ranney ML (2018) Using high-risk adolescents' voices to develop a comprehensible cognitive behavioral therapy-based text-message program. Behav Med 44(2):89-99. https://doi.org/10.1080/08964 289.2016.1223597

63. Forchuk C, Reiss J, Eichstedt J, Singh D, Collins K, Rudnick A, Walsh J, Ethridge P, Kutcher S, Fisman S (2016) The youthmental health engagement network: an exploratory pilot study of a smartphone and computer-based personal health record for youth experiencing depressive symptoms. Int J Ment Health 45(3):205222. https://doi.org/10.1080/00207411.2016.1204823

64. Gondek D, Edbrooke-Childs J, Velikonja T, Chapman L, Saunders F, Hayes D, Wolpert M (2017) Facilitators and barriers to personcentred care in child and young people mental health services: a systematic review. Clin Psychol Psychother 24(4):870-886. https://doi.org/10.1002/cpp.2052

65. Kim HS, Munson MR, McKay MM (2012) Engagement in mental health treatment among adolescents and young adults: a systematic review. Child Adolesc Soc Work J 29:241-266. https://doi. org/10.1007/s10560-012-0256-2 